\title{
On the relative merits of simple and advanced constitutive models in dynamic analysis of tunnels
}

\author{
S. KONTOE*, L. ZDRAVKOVIC*, D. M. POTTS* and C. O. MENKITI ${ }^{\dagger}$
}

This paper compares simple constitutive models that are widely used in engineering practice with more sophisticated methods in the context of a case study. In particular, four constitutive modelling approaches have been considered: a simple elasto-plastic constitutive model (modified Cam-clay), with and without Rayleigh damping; the same model coupled with a cyclic non-linear model that can simulate pre-yield hysteresis; and finally an advanced kinematic hardening model, which is an improved version of the Al-Tabbaa \& Wood two-surface model. These four approaches are used to analyse the seismic response of a section of the Bolu tunnels during the 1999 Duzce earthquake. To shed light on the performance of the constitutive models, simple site response finite-element analyses were first undertaken for the studied site, paying particular attention to the calibration of the Rayleigh damping parameters. The results of these analyses, in terms of maximum shear strain, were then used as input to an analytical elastic method (extended Hoeg method) for calculating the thrust and bending moment acting in the tunnel lining. Finally the results of dynamic time domain plane-strain analyses, employing the four adopted constitutive modelling approaches, are compared against field observations and results obtained by the extended Hoeg method, to investigate the ability of the models, of ranging complexity, to mimic soil response under seismic excitation.

KEYWORDS: constitutive relations; earthquakes; numerical modelling; tunnels
La présente communication compare de simples modèles constitutifs, très répandus en ingénierie, avec des méthodes plus sophistiquées, dans le contexte d'une étude de cas. Elle se penche, en particulier, sur quatre méthodes de modélisation constitutive : un simple modèle constitutif élastoplastique (Cam Clay modifié) avec et sans amortissement de Rayleigh, le mếme modèle accouplé avec un modèle non linéaire cyclique, en mesure de simuler une hystérésis pré-déformation, et, enfin, un modèle de durcissement cinématique évolué, version perfectionnée du modèle à deux surfaces d'Al-Tabbaa et Wood. On utilise ces quatre principes pour analyser la réaction sismique d'une section des tunnels de Bolu, au cours du tremblement de terre de Duzce, en 1999. Afin de clarifier les performances des modèles constitutifs, on a effectué en premier lieu de simples analyses aux éléments finis des réponses sur site, portant sur le site étudié, en se penchants en particulier sur le calibrage des paramètres d'amortissement de Rayleigh. On a utilisé ensuite les résultats de ces analyses, sur le plan des déformations maximales en cisaillement comme éléments de base pour une méthode analytique élastique (méthode étendue de Hoeg) pour calculer le poussée et le moment de flexion agissant sur le revêtement du tunnel. On effectue enfin une comparaison des résultats des analyses dans le domaine temporel de la déformation sur un plan, faisant usage des quatre méthodes de modélisation constitutives adoptées, avec les résultats obtenus à l'aide de la méthode étendue de Hoeg, pour examiner la capacité pour des modèles de complexité variable de simuler la réaction des sols à une excitation sismique.

\section{INTRODUCTION}

Understanding the behaviour of geotechnical structures such as tunnels, earthfill dams and retaining walls during earthquakes is recognised as a necessary condition for their rigorous and safe seismic design. In order to predict the seismic response of these structures correctly, it is essential to develop and use constitutive models that can simulate soil behaviour appropriately under dynamic loading. Numerical analysis has developed significantly over the last decades, and nowadays a wide range of constitutive models is available. Equivalent linear models and simple non-linear models are used with acceptable accuracy for situations involving small to medium strains, whereas for higher strain levels coupling of a non-linear model with an elasto-plastic model, or the use of more advanced models, is needed. However, not all of the above-mentioned types of models are available in commercial codes. Therefore in engineering practice very simple elasto-plastic models (e.g. Mohr-Coulomb and/or

Manuscript received 23 November 2009; revised manuscript accepted 12 August 2010. Published online ahead of print 25 January 2011. Discussion on this paper closes on 1 March 2012, for further details see $\mathrm{p}$. ii.

* Imperial College, London, UK.

$\dagger$ Geotechnical Consulting Group, London, UK.
Cam-clay type models) are often used for dynamic analysis. The inability of these models to reproduce hysteretic behaviour is usually compensated for by the use of Rayleigh damping.

In this paper four constitutive modelling approaches are considered: a simple elasto-plastic plastic constitutive model (modified Cam-clay), with and without Rayleigh damping; the same model coupled with a cyclic non-linear model that can simulate pre-yield hysteresis; and finally an advanced kinematic hardening model. These four approaches are used to analyse the seismic response of a section of the Bolu tunnels during the 1999 Duzce earthquake. The case study of the Bolu tunnels is extensively discussed by Kontoe et al. (2008a), and is chosen in this study as a well-documented example for which the relative merits of the employed constitutive models can be demonstrated. In order to shed light on the performance of the constitutive models simple, one-dimensional site response analyses were first undertaken for the studied site, paying particular attention to the calibration of the Rayleigh damping parameters. The results of these analyses, in terms of maximum shear strain, were also used as input to an analytical method (extended Hoeg method) for calculating the thrust and bending moment acting in the tunnel lining. Finally, the results of static analyses, to simulate the stresses acting on the tunnels' 
lining prior to the earthquake, and dynamic time domain plane-strain analyses employing the adopted constitutive approaches, are compared against field observations and results obtained from the extended Hoeg method.

\section{THE CASE STUDY}

In this section of the paper a brief overview of the Bolu tunnels case study is given to help the reader appreciate the problem analysed; more detailed descriptions can be found in Menkiti et al. (2001a), O'Rourke et al. (2001) and Kontoe et al. (2008a).

The $3.3 \mathrm{~km}$ long Bolu twin tunnels were excavated through highly variable ground conditions, consisting of extremely tectonised and sheared mudstones, siltstones and limestones, with thick layers of stiff, highly plastic fault gouge clay. The design solution that is relevant to the present study applies to the worst ground conditions, namely thick zones of plastic fault gouge clay. For such ground conditions two pilot tunnels were first constructed at the bench level and backfilled with concrete to serve as stiff abutments for further construction stages (see Kontoe et al., 2008a, for more details). The main tunnel was then advanced in three staggered headings. The bench pilot tunnels (BPTs) are themselves substantial structures with an external diameter of $5 \mathrm{~m}$, constructed by full-face excavation and supported with shotcrete and light steel ribs in $1.1 \mathrm{~m}$ round lengths. The bench pilot tunnels have a centre-to-centre separation of $19.0 \mathrm{~m}$, and were being progressed with the left BPT (LBPT) leading the right one.

When the Duzce earthquake struck the Bolu region in 1999, only about two-thirds of the tunnel alignment had been completed. Whereas the completed sections of the tunnels performed well, partly completed tunnels in poor ground, where only the initial support had been installed, suffered severe damage, and even collapse (Menkiti et al., 2001a; O'Rourke et al., 2001). The relevant area of the tunnels for this study is a zone of poor fault gouge clay, where collapses occurred over a length of $30 \mathrm{~m}$ in both bench pilot tunnels of the Asarsuyu drive, while the main tunnel had not yet been excavated. The BPTs were in perfect condition before the earthquake, having been constructed between 16 October and 12 November 1999, with the Duzce earthquake occurring on the evening of 12 November 1999. When the Duzce earthquake struck, the BPTs had not yet been back-filled with concrete, and were supported only by $30 \mathrm{~cm}$ thick shotcrete and HEB 100 steel ribs set at a $1.1 \mathrm{~m}$ longitudinal spacing.

\section{DESCRIPTION OF THE NUMERICAL MODEL Analysis arrangement}

Plane-strain analyses of the Bolu bench pilot tunnels (BPTs) were undertaken with the finite-element program ICFEP (Potts \& Zdravkovic, 1999). Fig. 1 shows the assumed stratigraphy and the position of BPTs for the stud-

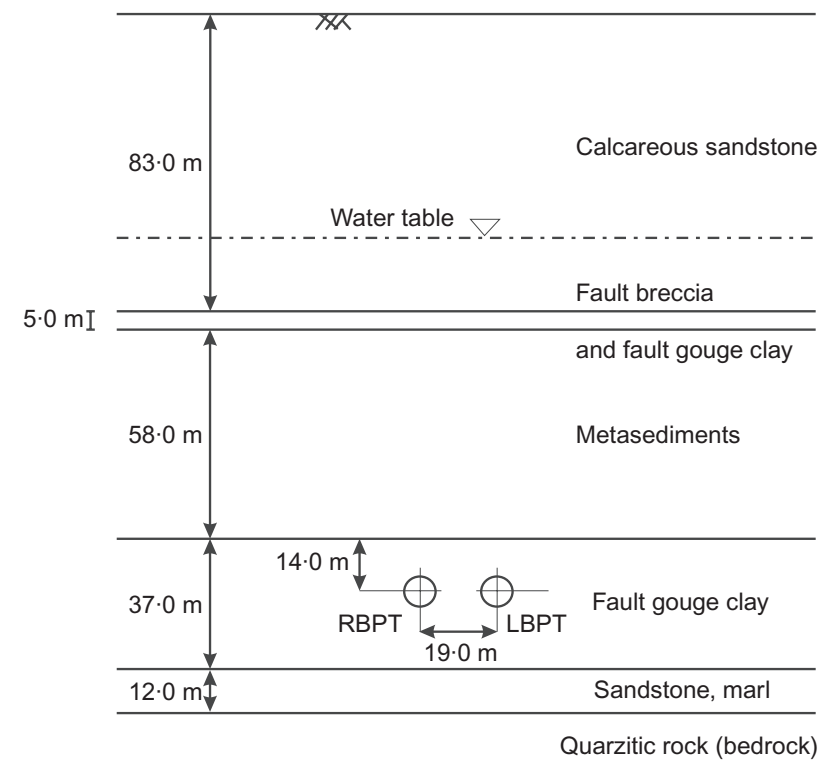

Fig. 1. Assumed ground profile (from Kontoe et al., 2008a) (C) 2008 NRC Canada or its licensors. Reproduced with permission

ied section (the centre of the tunnels is at $160 \mathrm{~m}$ depth); a description of the various geotechnical units, their index properties and the finite-element mesh can be found in Kontoe et al. (2008a). The strength properties (the angle of shearing resistance $\phi^{\prime}$, the cohesion $c^{\prime}$ and the undrained strength $S_{\mathrm{u}}$ ) and the estimated maximum elastic shear modulus $\left(G_{\max }\right)$ values are listed in Table 1 .

When the earthquake struck, considerable static stresses were acting on the tunnel linings, owing to the overburden pressure and the construction process. Hence, prior to all two-dimensional dynamic analyses with the four constitutive models considered in this study, a static analysis with the corresponding model was undertaken to establish the initial stresses acting on the lining. Undrained behaviour was assumed for the clay units, by setting the bulk modulus of the pore fluid to be much larger than the bulk modulus of the soil skeleton, and drained conditions were assumed for the rock layers. The construction of the tunnels was very quick; therefore the undrained assumption for the clay units is justified. Furthermore, some preliminary coupled analyses (with a rough estimate of the permeability for the clay) did not show any significant pore water pressure dissipation.

The lining of the tunnels was modelled with beam elements, and for all the analyses it was assumed to behave in a linear elastic manner. The beam elements were generated within the mesh at the beginning of the analysis (i.e. in increment 0 , which corresponds to the mesh generation stage). The tunnel construction was modelled using the convergence-confinement method (Panet \& Guenot, 1982), which is described in detail by Potts \& Zdravkovic (2001). The excavation of the BPTs was performed in 10 incre-

Table 1. Estimated strength and stiffness parameters

\begin{tabular}{|c|c|c|c|c|c|c|}
\hline & \multicolumn{2}{|c|}{$\phi^{\prime}$ : degrees } & \multicolumn{2}{|c|}{$c^{\prime}: \mathrm{kPa}$} & \multirow[t]{2}{*}{$S_{\mathrm{u}}: \mathrm{kPa}$} & \multirow[t]{2}{*}{$G_{\max }: \mathrm{MPa}$} \\
\hline & Peak & Residual & Peak & Residual & & \\
\hline $\begin{array}{l}\text { Calcareous sandstone } \\
\text { Fault breccia and fault gouge clay } \\
\text { Metasediments } \\
\text { Fault gouge clay } \\
\text { Sandstone, siltstone with marl fragments }\end{array}$ & $\begin{array}{l}25-30 \\
13-16 \\
25-30 \\
18-24 \\
25-30\end{array}$ & $\begin{array}{r}20-25 \\
9-12 \\
20-25 \\
6-12 \\
20-25\end{array}$ & $\begin{array}{r}50 \\
100 \\
50 \\
100 \\
50\end{array}$ & $\begin{array}{l}25 \\
50 \\
25 \\
50 \\
25\end{array}$ & $\begin{array}{r}700 \\
1000 \\
1350 \\
1000 \\
1500\end{array}$ & $\begin{array}{r}1000 \\
750 \\
1500 \\
850 \\
2500\end{array}$ \\
\hline
\end{tabular}


ments, and the linings were constructed prior to the completion of excavation. The geometrical and material properties of the BPTs' linings are summarised in Kontoe et al. (2008a).

The width of the mesh was selected to be $219 \mathrm{~m}$, and the repeated boundary condition (tied node boundary) was applied along the vertical sides of the mesh during the dynamic analysis. All layers were assumed to behave undrained for the dynamic analyses. The majority of the Bolu tunnels, including the section of interest, run $\mathrm{N}-\mathrm{S}$. The $\mathrm{E}-\mathrm{W}$ component of the Bolu station ground motion (i.e. parallel to the fault rupture) is the one responsible for the shear deformation of the tunnels' transverse cross-section, and was employed in all dynamic FE analyses, after scaling it to $70 \%$ to account for strong motion attenuation with depth. The scaled acceleration time history was applied incrementally in the horizontal direction to all nodes along the bottom boundary of the FE model (i.e. along the bedrock/sandstone interface), while the corresponding vertical displacements were restricted. The peak value of the input acceleration time history is $0.57 \mathrm{~g}$, and it occurs approximately $5.8 \mathrm{~s}$ after the onset of the excitation. The time integration was performed with the generalised- $\alpha$ method (Chung \& Hulbert, 1993; Kontoe et al., 2008b) with a time step, $\Delta t=0.01 \mathrm{~s}$. The time step value was selected based on a preliminary parametric study, which showed that $\Delta t=0.01 \mathrm{~s}$ gives an accurate solution (compared with analyses with smaller time step) and reasonable computation time. Generally, the lower the time step, the lower the numerical damping (and hence the higher the numerical noise). The adopted integration scheme achieves optimum filtering of the high-frequency noise, without affecting the low-frequency response. For the frequency range of the examined problem, and with the use of the generalised- $\alpha$ method, there were no issues of numerical noise.

\section{Constitutive models used in the analyses}

The aim of this study is to highlight the relative merits of simple constitutive models that are typically used in engineering practice, and of more sophisticated models that are used mainly for research purposes, in time domain dynamic analyses. Therefore the following four modelling approaches were considered.

(a) A variant of the modified Cam-clay (MCC) model (Roscoe \& Burland, 1968; Potts \& Zdravkovic, 1999) was used to describe the plastic yielding behaviour of the soil (this model adopts a Mohr-Coulomb hexagon for the shape of the yield surface in the deviatoric plane) and a variant of the small-strain stiffness model of Jardine et al. (1986) (Potts \& Zdravkovic, 1999) was used to describe the non-linear elastic pre-yield behaviour. This approach is hereafter referred to as MCCJ.

(b) The same combination of constitutive models (i.e. MCC and Jardine et al., 1986) as in the first approach was considered, but with the addition of Rayleigh damping (hereafter referred to as MCCJ-R).

(c) A cyclic non-linear model was used to describe the non-linear elastic pre-yield behaviour coupled with the MCC model, which describes the plastic yielding behaviour of the soil. The pre-yield non-linear model adopts a hyperbolic function for the backbone curve, and follows the Masing rules for unloading and reloading, as described in Taborda et al. (2009). This third approach is notated as MCCT.

(d) A two-surface kinematic hardening model (M2-SKH), which is an improved version of the Al-Tabbaa \& Wood (1989) model developed by Grammatikopoulou et al.
(2006), was used. The M2-SKH model is an extension of the MCC model, as it introduces a small kinematic yield surface within the MCC bounding surface. The behaviour within the small kinematic yield surface (KYS) is elastic, but it becomes elasto-plastic when the stress state engages the KYS. Plasticity is introduced by both the movement (kinematic hardening) and the change of size (isotropic hardening) of the KYS.

Elasto-plastic constitutive laws similar to the MCCJ and MCCJ-R models have been widely used to study the seismic response of tunnels (e.g. Pakbaz \& Yareevan, 2005; Pellet et al., 2005; Hwang \& Lu, 2007; Amorosi \& Boldini, 2009) or other geotechnical structures (e.g. Madabhushi \& Zeng, 2006; Leger \& Javanmardi, 2007; Rampello et al., 2009), as they are available in most commercial codes. On the other hand, the use of more advanced approximations like MCCT and M2-SKH is gradually becoming more and more popular as the geotechnical community becomes more familiar with their use (e.g. Elia et al., 2005; Ni, 2007; Sun et al., 2008). In all cases it is important to appreciate the basic facets of each model, and their effects on the analysis results.

The MCC model requires three compression parameters (the slope of the virgin compression line $\lambda$, the slope of the swelling line $\kappa$ and the specific volume at unit pressure $v_{1}$ on the virgin compression line), one drained strength parameter $\left(\phi^{\prime}\right)$ and one elastic parameter (the maximum shear modulus $G$ ). In the absence of oedometer test data, typical values of compression parameters for stiff clays/soft rocks were used (all MCC parameters are listed in the Appendix of Kontoe et al., 2009). For the two non-linear elastic models (i.e. the variant of Jardine et al. in MCCJ and MCCJ-R, and of Taborda et al. in MCCT) the secant shear stiffness variations with deviatoric strain of the clayey layers and the metasediments were matched to data from pressuremeter tests. Since there was no information available regarding the shear stiffness degradation of the sandstones (i.e. layers 1 and 5), the two sandstones were assumed to have similar shear stiffness degradation as the metasediments (i.e. layer 3). The parameters used for the different geological units in the modified Jardine et al. model are detailed in Kontoe et al. (2009), and the parameters used in the Taborda et al. model are given in the Appendix.

The M2-SKH model requires, in total, seven parameters. Five of them have their origin in the MCC model $\left(\lambda, \kappa, v_{1}\right.$, $\left.\phi^{\prime}, G\right)$, and the remaining two parameters $\left(R_{\mathrm{b}}, \alpha_{\mathrm{o}}\right)$ define the behaviour of the kinematic surface. Based on the available pressuremeter test data, the ratio of the size of the kinematic surface to that of the bounding surface, $R_{\mathrm{b}}$, was assumed to be $0 \cdot 1$ for the two clays and $0 \cdot 15$ for the soft rock layers; the parameter $\alpha_{0}$, which controls the decay of stiffness, was taken equal to 15.0 for all layers.

Figure 2 compares normalised secant stiffness decay curves resulting from undrained triaxial extension single element simulations, computed with the four constitutive models, with pressuremeter data for a point corresponding to the middle of layer 4 (fault gouge clay). It is interesting to note that the observed abrupt change in stiffness degradation predicted by the MCCJ (at approximately $0 \cdot 15 \%$ strain) and MCCT (at approximately $0 \cdot 4 \%$ strain) models occurs when the stress path reaches the MCC yield surface. Similar model calibration procedures were followed for all layers.

\section{RAYLEIGH DAMPING}

As previously mentioned, for the MCCJ-R analyses Rayleigh damping was used to mitigate the inability of the MCCJ model to simulate appropriately hysteretic damping (Kontoe et al., 2009). Rayleigh damping is a frequency- 


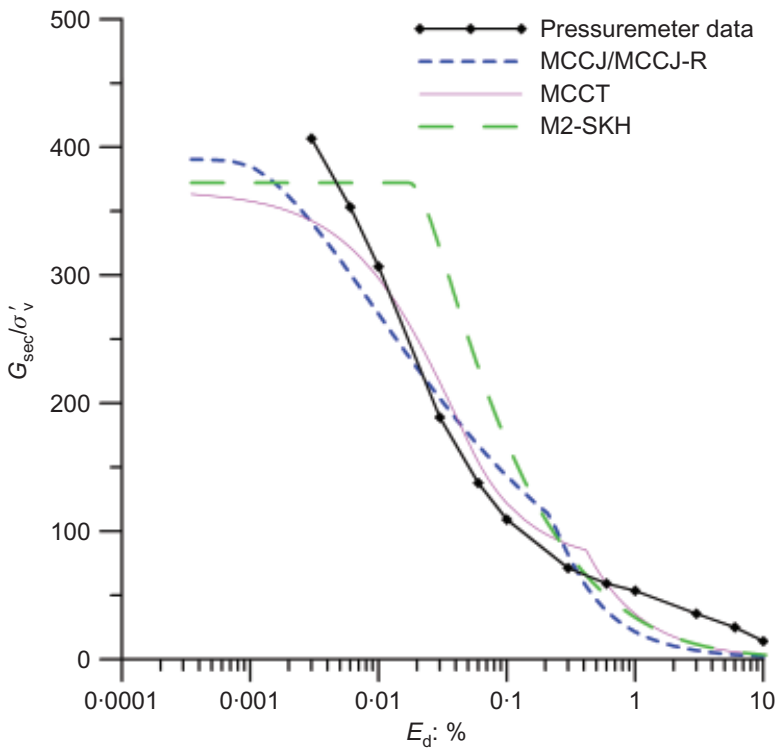

Fig. 2. Normalised secant shear stiffness decay curves resulting from undrained triaxial single-element simulation and pressuremeter data for fault gouge clay of layer 4

dependent viscous damping that formulates the damping matrix as a linear combination of the mass and the stiffness matrices (e.g. Chopra, 2001) according to the equation

$$
[C]=\alpha[M]+\beta[K]
$$

where $[M]$ and $[K]$ are the mass and stiffness matrices respectively, and $\alpha$ and $\beta$ are the mass-proportional and stiffness-proportional damping coefficients respectively. These coefficients are related to the target damping ratio $\xi_{\mathrm{t}}$ through the relationship

$$
\begin{aligned}
& \alpha=\frac{2 \omega_{1} \omega_{2} \xi_{\mathrm{t}}}{\omega_{1}+\omega_{2}} \\
& \beta=\frac{2 \xi_{\mathrm{t}}}{\omega_{1}+\omega_{2}}
\end{aligned}
$$

where $\omega_{1}, \omega_{2}$ are the two frequencies defining the frequency range over which the damping is equal to or lower than $\xi_{\mathrm{t}}$. Clearly, Rayleigh damping is only an approximate way to reproduce material damping, as it is not related to the induced strain level, while the level of damping (i.e. target damping ratio) is decided a priori, and does not result from the material behaviour.
Since in reality damping in soils is almost independent of frequency, it is common practice to try to get the right 'target' damping for the important frequencies of the problem. The natural angular frequencies of a given mode $\left(\omega_{n}\right)$ are usually estimated, assuming a uniform soil layer on a rigid base, as

$$
\omega_{n}=2 \pi(2 n-1) \frac{V_{\mathrm{s}}}{4 H}
$$

where $n$ is the mode number, $V_{\mathrm{s}}$ is the shear wave velocity and $H$ is the height of the soil column. Zerwer et al. (2002) showed that this can be achieved to a certain extent by taking $\omega_{1}$ as the first natural frequency of the system and $\omega_{2}$ as the highest natural frequency of the vibration modes with a high contribution to the response. More recently Kwok et al. (2007) recommended, for site response analysis, the use of the site frequency as $\omega_{1}$ and five times the site frequency (i.e. the frequency of the third mode) as $\omega_{2}$.

The selection of the Rayleigh parameters is highly dependent on the problem analysed, and on the frequency content of the input motion. Therefore in this study a calibration procedure was followed to decide both an appropriate target damping ratio and a suitable frequency range $\omega_{1}-\omega_{2}$. This is set out below.

Initially an equivalent linear analysis of a soil column, corresponding to the stratigraphy shown in Fig. 1 and subjected to the Bolu acceleration time history, was undertaken with the software EERA of Bardet et al. (2000) (thereafter referred to as EERA-1), which is an application of SHAKE 91. The purpose of this analysis is to decide on an average target damping ratio for each layer, which is then used for the calibration of the Rayleigh constants used in the FE analysis. The shear stiffness degradation curves used in the EERA-1 analysis were based on the secant shear modulus curves adopted for the Jardine et al. (1986) model for the middle point of each layer (see Kontoe et al., 2009). In addition, the damping ratio curves of Vucetic \& Dobry (1991) for overconsolidated clays with a plasticity index of 50 were adopted for the two clay layers, while for the remaining rock strata the lower limit of Seed et al.'s (1986) range of damping ratio curves for sands was employed. The resulting damping ratios, that is, the converged values from the equivalent linear analysis (EERA-1), are given in Table 2 , column two. These values were then adopted as the target damping ratios, $\xi_{t}$, as they account for both the stiffness degradation and the damping variation with strain for the whole soil column. In the next section of the paper, EERA-1

\begin{tabular}{|c|c|c|c|c|c|c|c|c|c|}
\hline & & \multicolumn{2}{|c|}{ ELA-R1 } & \multicolumn{2}{|c|}{ ELA-R2 } & \multicolumn{2}{|c|}{ ELA-R3 } & \multicolumn{2}{|c|}{ ELA-R4 } \\
\hline & & $\omega_{1}: \mathrm{rad} / \mathrm{s}$ & $\omega_{2}: \mathrm{rad} / \mathrm{s}$ & $\omega_{1}: \mathrm{rad} / \mathrm{s}$ & $\omega_{2}: \mathrm{rad} / \mathrm{s}$ & $\omega_{1}: \mathrm{rad} / \mathrm{s}$ & $\omega_{2}: \mathrm{rad} / \mathrm{s}$ & $\omega_{1}: \mathrm{rad} / \mathrm{s}$ & $\omega_{2}: \mathrm{rad} / \mathrm{s}$ \\
\hline & & $\begin{array}{c}6 \cdot 145 \\
(1 \mathrm{st} \text { mode })\end{array}$ & $\begin{array}{l}62 \cdot 83 \text { (highest } \\
\text { input } \\
\text { frequency) }\end{array}$ & $\begin{array}{c}6 \cdot 145 \\
(1 \mathrm{st} \text { mode })\end{array}$ & $\begin{array}{c}43 \cdot 02 \\
\text { (4th mode) }\end{array}$ & $\begin{array}{c}6 \cdot 145 \\
(1 \mathrm{st} \text { mode) }\end{array}$ & $\begin{array}{c}30 \cdot 725 \\
\text { (3rd mode) }\end{array}$ & $\begin{array}{c}6 \cdot 145 \\
(1 \mathrm{st} \text { mode })\end{array}$ & $\begin{array}{c}18 \cdot 435 \\
\text { (2nd mode) }\end{array}$ \\
\hline Layer & $\begin{array}{c}\text { Target } \\
\text { damping } \\
\text { ratio, } \xi_{\mathrm{t}}: \%\end{array}$ & $\alpha$ & $\beta$ & $\alpha$ & $\beta$ & $\alpha$ & $\beta$ & $\alpha$ & $\beta$ \\
\hline $\begin{array}{l}1 \\
2 \\
3 \\
4 \\
5\end{array}$ & $\begin{array}{c}7 \\
11 \\
8 \\
11 \\
4 \cdot 7\end{array}$ & $\begin{array}{l}0.7837 \\
1.2316 \\
0.8957 \\
1.2316 \\
0.5262\end{array}$ & $\begin{array}{l}2.03 \times 10^{-3} \\
3 \cdot 19 \times 10^{-3} \\
2 \cdot 32 \times 10^{-3} \\
3 \cdot 19 \times 10^{-3} \\
1 \cdot 63 \times 10^{-3}\end{array}$ & $\begin{array}{l}0 \cdot 7528 \\
1 \cdot 183 \\
0 \cdot 8604 \\
1 \cdot 183 \\
0 \cdot 5055\end{array}$ & $\begin{array}{l}2 \cdot 850 \times 10^{-3} \\
4.475 \times 10^{-3} \\
3.254 \times 10^{-3} \\
4.475 \times 10^{-3} \\
1.912 \times 10^{-3}\end{array}$ & $\begin{array}{l}0 \cdot 717 \\
1 \cdot 1267 \\
0 \cdot 8194 \\
1 \cdot 1267 \\
0 \cdot 4814\end{array}$ & $\begin{array}{l}3.797 \times 10^{-3} \\
5.966 \times 10^{-3} \\
4.339 \times 10^{-3} \\
5.966 \times 10^{-3} \\
2.549 \times 10^{-3}\end{array}$ & $\begin{array}{l}0 \cdot 64528 \\
1 \cdot 014 \\
0 \cdot 7375 \\
1 \cdot 014 \\
0 \cdot 4333\end{array}$ & $\begin{array}{l}5.695 \times 10^{-3} \\
8 \cdot 95 \times 10^{-3} \\
6 \cdot 509 \times 10^{-3} \\
8.95 \times 10^{-3} \\
3 \cdot 824 \times 10^{-3}\end{array}$ \\
\hline
\end{tabular}
is used as a reference linear analysis for comparison with other non-linear analyses.

Table 2. Summary of target damping ratios and Rayleigh damping parameters for all layers 
The linear analysis was then repeated using the maximum shear stiffness for each layer (which was not now allowed to vary with strain) and the damping ratios listed in Table 2, which were also fixed with strain. This analysis was called EERA-2, and its purpose was to obtain another reference linear analysis for comparison with $\mathrm{FE}$ one-dimensional linear analyses, now described. Four one-dimensional column linear elastic FE analyses (ELA-R1 to ELA-R4) were undertaken for the same stiffness and target damping values, but employing different combinations of $\omega_{1}$ and $\omega_{2}$ to calculate the damping matrix $C$, as shown in Table 2 and equations (1) and (2). The purpose of these FE analyses was to illustrate the impact of the adopted Rayleigh damping frequency range on the analyses output by comparison with EERA-2. To fully appreciate the dependence of Rayleigh damping on frequency, Fig. 3 shows the variation of damping ratio with frequency for the fault gouge clay (layers 2 and 4) employing equations (1) and (2) and the $\alpha$ and $\beta$ parameters used in the ELA-R set of analyses (shown in Table 2). Fig. 4(a) compares the significant part (i.e. $t=4-$ $10 \mathrm{~s}$ ) of the acceleration time histories for a node at a depth of $z=157.4 \mathrm{~m}$ (i.e. in the fault gouge clay, at the level of the tunnels' crown) for the EERA-2 and the ELA-R set of analyses. The ELA-R4 analysis, which is based on the first and second modes (see Table 2), agrees very well with the EERA-2 analysis, whereas all other ELA-R analyses overpredict the response. The Fourier spectra plots of Fig. 4(b) show that most of the frequency content of the response is within the range of frequencies of $0.2-3.5 \mathrm{~Hz}$. For most frequencies of this range the analyses ELA-R1 to ELA-R3 have much lower damping than the target damping ratio of $11 \%$ (see Fig. 3), and therefore they overestimate the peak that corresponds to the second mode (at approximately $2 \cdot 8 \mathrm{~Hz}$ ) in Fig. 4(b). Similar results were observed for the remaining four soil layers. Therefore it was concluded that for the specific input motion and stratigraphy the calibration of the Rayleigh damping should be based on the first and second modes. The parameters of the ELA-R4 analysis were used in all subsequent analyses involving Rayleigh damping. The above-described procedure of calibration is essential for a rigorous selection of both the target damping ratio and the Rayleigh damping parameters.

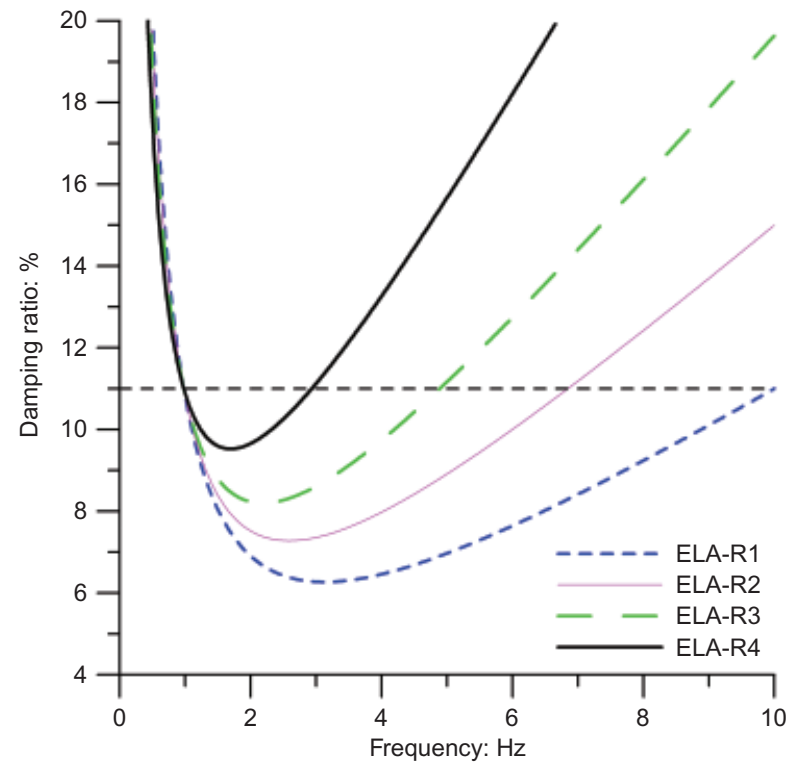

Fig. 3. Damping ratio variation with frequency analyses for layers 2 and 4 (target damping ratio $11 \%$ )

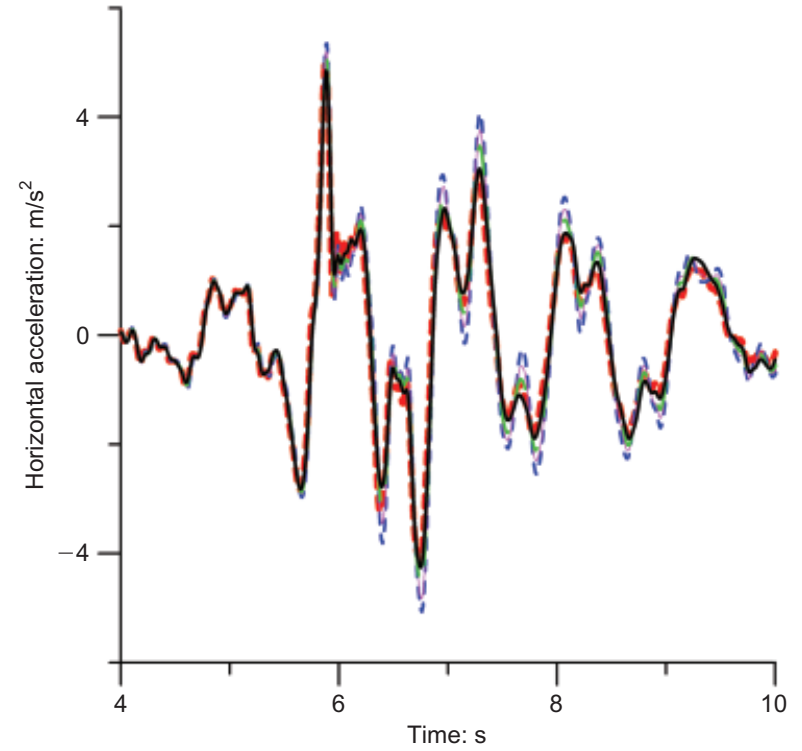

(a)

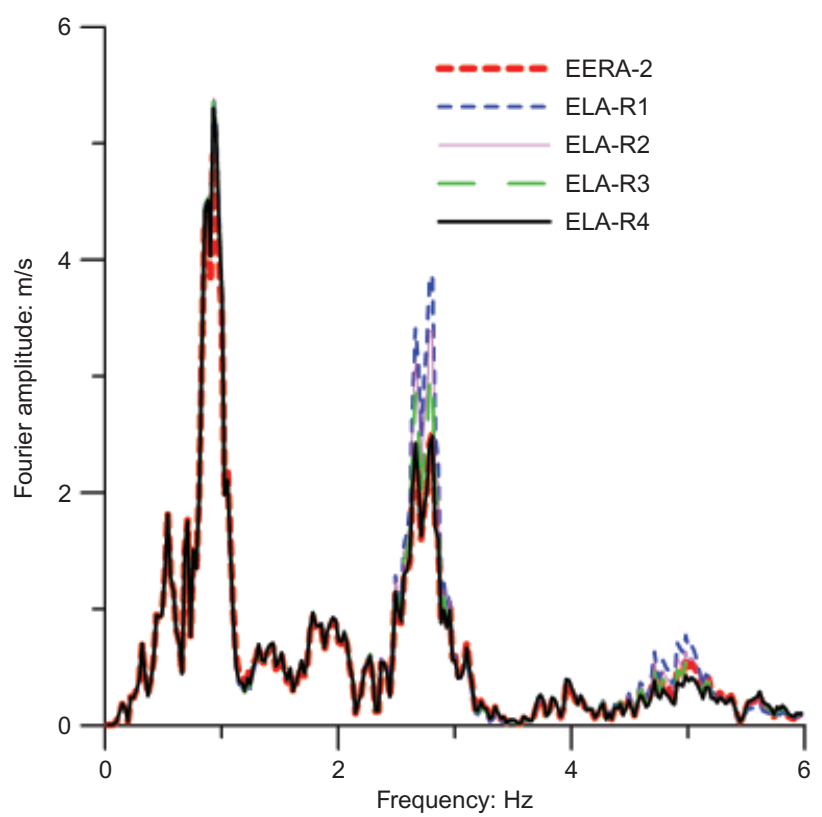

(b)

Fig. 4. (a) Acceleration time histories and (b) acceleration Fourier spectra for node at depth of $157 \cdot 4 \mathrm{~m}$

\section{ONE-DIMENSIONAL ANALYSES AND SIMPLIFIED METHOD OF ANALYSIS}

Owing to the complexity and the high computational cost of dynamic soil structure interaction FE analyses, it is often preferred to employ simplified analytical solutions to investigate the seismic response of tunnels. The extended Hoeg ${ }^{\S}$ method (Hoeg, 1968; Schwartz \& Einstein, 1980), assuming either full-slip or non-slip conditions along the interface between the ground and the lining, expresses the maximum thrust $\left(T_{\max }\right)$ and the maximum bending moment $\left(M_{\max }\right)$ of the tunnel lining as a function of the maximum free-field shear strain $\left(\gamma_{\max }\right)$ at the level of the tunnel and the properties of the soil and the lining. (This method was later summarised by Wang (1993), and thus it is often referred to in the literature as the 'Wang method'.) The combined effects of thrust and bending moment can be then examined by calculating the maximum hoop stress, $\sigma_{\mathrm{H}}$, at the extreme fibre of the lining as 


$$
\sigma_{\mathrm{H}}=\frac{T}{A}+\frac{|M| y}{I}
$$

where $y$ is the distance from the neutral axis to the extreme fibre of the lining cross-section, and $\mathrm{A}$ is the area per unit width of the lining cross-section. It should be noted that the $\gamma_{\max }$ at the level of the tunnels is commonly calculated from a one-dimensional site response analysis (Hashash et al., 2001). Consequently, the predicted bending moments and thrust forces are highly dependent on the site response analysis results. It is thus interesting to explore the sensitivity of the extended Hoeg method to the constitutive model used for the site response analysis.

Undrained dynamic FE one-dimensional column analyses were undertaken with the MCCJ, MCCJ-R, MCCT and M2SKH models to calculate the maximum free-field shear strain at the level of the tunnels. This set of analyses was also used to demonstrate some fundamental features of the employed constitutive models, and is compared with the equivalent linear EERA-1 analysis. The comparison with the equivalent linear method does not serve any validation purposes, as this method has several limitations, and it is based on different assumptions from that of the FE models; however, it provides a useful reference solution. The one-dimensional FE model is $1 \mathrm{~m}$ wide, and the spatial discretisation in the vertical direction is the same as that of the two-dimensional mesh in the far field. The boundary conditions along the bottom and the lateral boundaries of the mesh are those previously described for the two-dimensional model.

Figure 5 plots the loci of maximum acceleration and shear strain with depth, computed with all models and EERA-1. In terms both of acceleration and of shear strain values, the MCCJ model predicts a much higher response, especially in the clay layers. On the other hand, all other analyses (i.e. MCCJ-R, MCCT, M2-SKH and EERA-1) predict similar maximum acceleration profiles, showing that the soil stratigraphy does not amplify the bedrock motion. The MCCT and MCCJ-R models give considerably higher strains for the thin clay layer (i.e. at $83 \mathrm{~m}$ depth) than the M2-SKH and EERA-1 analyses. The MCCT model also predicts higher strain values for the fault gouge clay layer at the level of the tunnels than all other models (excluding the MCCJ).

Table 3 summarises the results of the extended Hoeg approach for the BPTs for no-slip conditions, using the maximum shear strain at a depth of $157.5 \mathrm{~m}$ (i.e. corresponding to the tunnels' crown level) computed with all models. Clearly, the resulting hoop stress is highly dependent on the adopted constitutive model. As expected, based on the results of Fig. 5(b), the MCCJ model predicts much higher loads than any other approach, the EERA-1, MCCJ-R and M2-SKH models give similar values, and the MCCT gives 54\% higher hoop stress for both tunnels than EERA-1. This comparison highlights the effects of the employed constitutive model, even when adopting simplified methods of analysis.

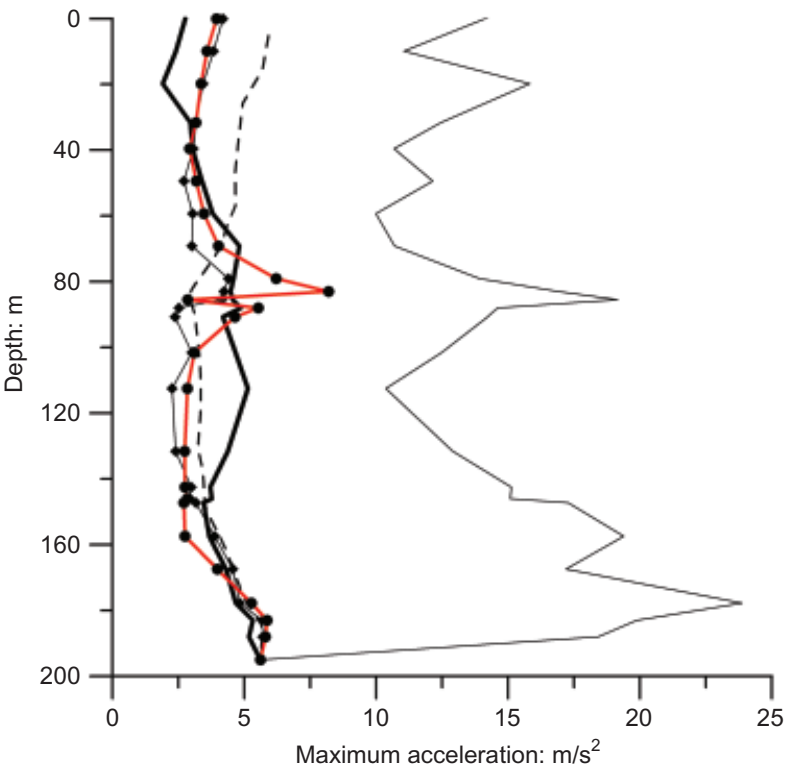

(a)

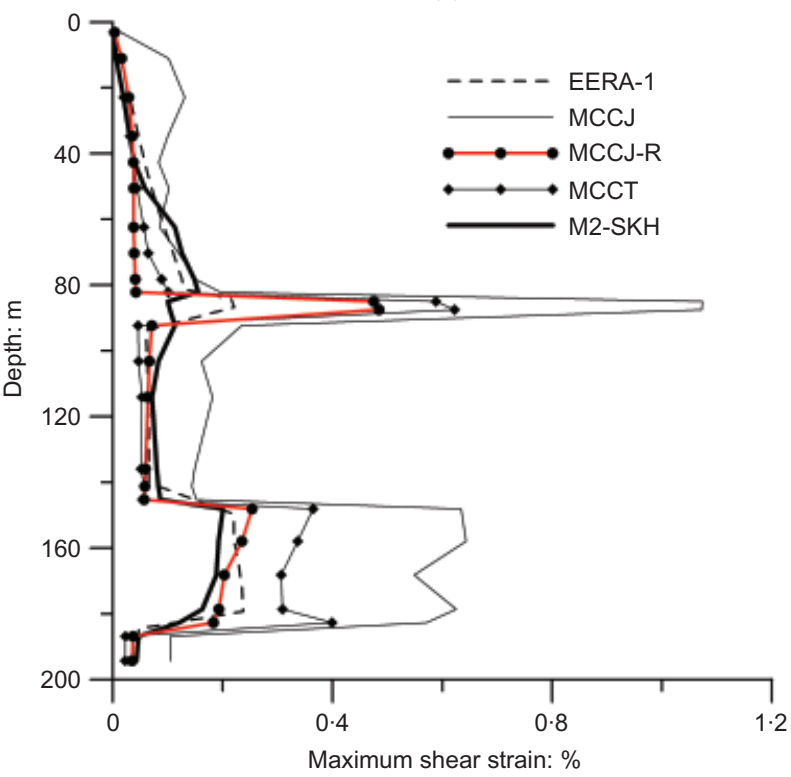

(b)

Fig. 5. (a) Maximum acceleration and (b) shear strain profiles computed with MCCJ, MCCJ-R, MCCT, M2-SKH models and EERA-1

Figure 6 plots strain time histories at a depth of $z=157.5 \mathrm{~m}$ for all modelling approaches. The MCCJ analysis predicts unrealistic behaviour, as the intense period of the motion cannot be distinguished and the response appears to be undamped, indicating that the introduced plasticity in the MCCJ analysis does not provide adequate damping in

Table 3. Summary of extended Hoeg method results for LBPT (no-slip conditions)

\begin{tabular}{|c|c|c|c|c|c|c|c|}
\hline & \multirow{2}{*}{$\begin{array}{l}\text { Free-field shear } \\
\text { strain at level of } \\
\text { tunnels, } \gamma_{\mathrm{ff}}: \%\end{array}$} & \multicolumn{2}{|c|}{$\begin{array}{l}\text { Max. thrust in tunnel lining, } T_{\max } \text { : } \\
\qquad \mathrm{kN} / \mathrm{m}\end{array}$} & \multicolumn{2}{|c|}{$\begin{array}{l}\text { Max. bending moment in tunnel } \\
\text { lining, } M_{\max }: \mathrm{kNm} / \mathrm{m}\end{array}$} & \multicolumn{2}{|c|}{$\begin{array}{l}\text { Max. hoop stress, } \sigma_{\mathrm{H}} \text { : } \\
\qquad \mathrm{MPa}\end{array}$} \\
\hline & & LBPT & RBPT & LBPT & RBPT & LBPT & RBPT \\
\hline $\begin{array}{l}\text { EERA-1 } \\
\text { MCCJ } \\
\text { MCCJ-R } \\
\text { MCCT } \\
\text { M2-SKH }\end{array}$ & $\begin{array}{l}0 \cdot 22 \\
0 \cdot 64 \\
0 \cdot 24 \\
0 \cdot 34 \\
0 \cdot 19\end{array}$ & $\begin{array}{r}4584 \cdot 3 \\
13336 \cdot 1 \\
5001 \cdot 0 \\
7084 \cdot 8 \\
3959 \cdot 2\end{array}$ & $\begin{array}{r}4333 \cdot 7 \\
12607 \cdot 1 \\
4727 \cdot 6 \\
6697 \cdot 5 \\
3742 \cdot 7\end{array}$ & $\begin{array}{l}236 \cdot 9 \\
689 \cdot 2 \\
258 \cdot 5 \\
366 \cdot 2 \\
204 \cdot 6\end{array}$ & $\begin{array}{l}178 \cdot 7 \\
520 \cdot 0 \\
195 \cdot 0 \\
276 \cdot 2 \\
154 \cdot 4\end{array}$ & $\begin{array}{l}31 \cdot 1 \\
90 \cdot 4 \\
33 \cdot 9 \\
48 \cdot 0 \\
26 \cdot 8\end{array}$ & $\begin{array}{l}26 \cdot 36 \\
76 \cdot 7 \\
28 \cdot 8 \\
40 \cdot 7 \\
22 \cdot 8\end{array}$ \\
\hline
\end{tabular}




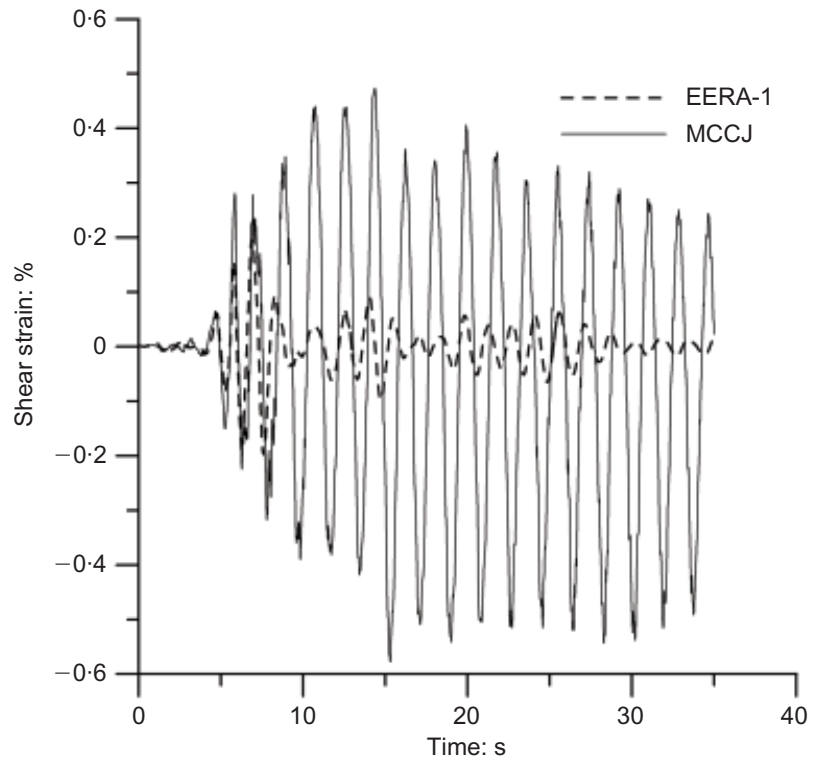

(a)

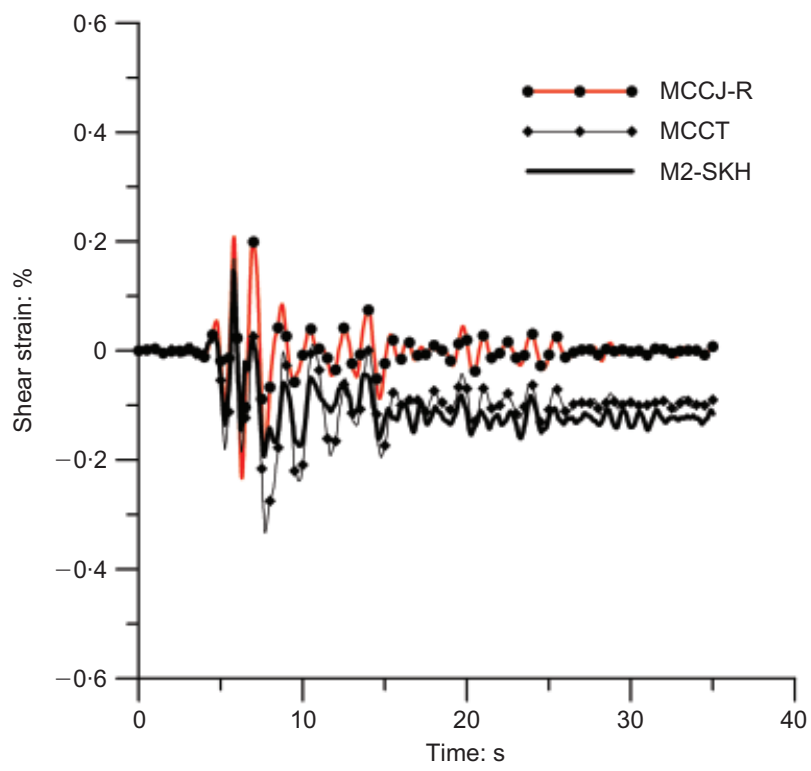

(b)

Fig. 6. Representative strain-time histories for fault gouge clay at integration point at depth $z=\mathbf{1 5 7 . 5} \mathrm{m}$ computed with: (a) MCCJ model; (b) MCCJ-R, MCCT and M2-SKH models

the response. The strain histories predicted by the EERA-1 and MCCJ-R analyses are similar, and they both result in zero irreversible strains. The MCCT model predicts generally higher strain levels than the M2-SKH model, but in terms of irreversible strains after the intense period of the earthquake (i.e. $t>15 \mathrm{~s}$ ) they both predict similar values.

The above-mentioned limitations of the MCCJ model are better illustrated in Figs 7(a) and 8(a), which present the $p^{\prime}-$ $J$ stress path (where $J$ is a measure of the distance of the current stress state from the space diagonal in the deviatoric plane) and the shear stress-strain curve respectively of an integration point at a depth of $z=157.5 \mathrm{~m}$. The stress path starts from point A (within the yield surface) and reaches the yield surface for first time at point $\mathrm{C}$, at $t=9.82 \mathrm{~s}$, well after the peak of the earthquake. Therefore during the first $9 \cdot 82 \mathrm{~s}$ of the analysis (i.e. path $\mathrm{ABC}$ ) the behaviour is non-linear elastic, with zero hysteretic damping. Subsequently, the stress state reaches the yield surface numerous times, generating some plastic strains and travelling towards the critical state (point D), but each time it stays there only for a very short time, since as a result of unloading it is forced to move back into the elastic region. This results in a more or less nonlinear elastic behaviour rather than a non-linear elasto-plastic behaviour. It should be noted also that the minor axis of the yield surface changes size during the earthquake owing to the variation of Lode's angle, while the change in size of the major axis is so small that it is impossible to distinguish it in Fig. 7(a).

The stress path of the MCCJ-R analysis (Fig. 7(b)) always stays inside the yield surface, generating zero plastic strains and zero hysteretic damping (see also Fig. 8(b)). Therefore the analysis is purely non-linear elastic, damping is introduced only through the Rayleigh damping formulation and the role of the elasto-plastic model is in reality redundant. This explains the similarity of the shear strain time histories of the analyses EERA-1 and MCCJ-R (Fig. 6).

The stress path of the MCCT analysis, although staying well within the yield surface and consequently generating zero plastic strains, develops hysteretic loops (Fig. 8(c)). The area of these loops represents the energy dissipated during the corresponding cycle. During the intense period of the earthquake $(t<9.82 \mathrm{~s})$ the hysteretic loops of the MCCT model are dominated by the specified minimum stiffness (see Appendix), while for $t>9.82 \mathrm{~s}$ the loops are quite similar to those generated by the M2-SKH model (Fig. $8(d))$.

For the M2-SKH analysis, the stress state starts from a point inside the kinematic yield surface (KYS) (point A, Fig. 7(d)), oscillates for a while within this surface along a linear stress-strain path, and at $t=3.68 \mathrm{~s}$ reaches the extremity of the KYS (point B) for the first time. From this point onwards, plasticity is introduced into the analysis, even in unloading, as the KYS changes size (only slightly though) and most importantly as it is dragged around within the bounding surface. From point B onwards the behaviour is highly non-linear, and the stress reversals (e.g. at point $\mathrm{C}$ ) produce significant hysteresis loops. Clearly, as the intensity of the excitation reduces (for $t>9.82 \mathrm{~s}$ ), the hysteresis loops become very narrow, resulting in lower damping.

\section{TWO-DIMENSIONAL ANALYSES RESULTS}

Static analyses

As previously discussed, prior to all two-dimensional dynamic analyses a static analysis was undertaken to establish the initial stresses acting on the lining of the tunnels before the earthquake. Fig. 9 shows an enlarged view of the original and final mesh (i.e. at the last increment of the static analysis) configurations around the tunnels. The static stresses acting on the tunnels' lining cause an elliptical deformed shape, which is slightly more pronounced in the RBPT. It is interesting to note that, whereas the MCCJ/ MCCJ-R and MCCT analyses predict the major axis of the ellipse to be horizontally aligned, for the M2-SKH analysis the major axis is vertically aligned. However, all analyses predict horizontal diametral convergence, as summarised in Table 4. The MCCJ/MCCJ-R analyses predict very similar movements to those predicted by the MCCT model, whereas the M2-SKH analysis predicts slightly higher values. Measurements from monitoring an exploratory pilot tunnel in a flyschoid clay (not at the sections considered herein) reported by Menkiti et al. (2001b) indicate a horizontal convergence of $15-25 \mathrm{~mm}$, which is lower than all FE predictions of Table 4. However, it is also reported that the exploratory pilot tunnel experienced much larger movements in the fault gouge clay. Furthermore, measurements from a completed section of the left main tunnel in gouge clay show a horizontal diametral convergence of the BPT con- 


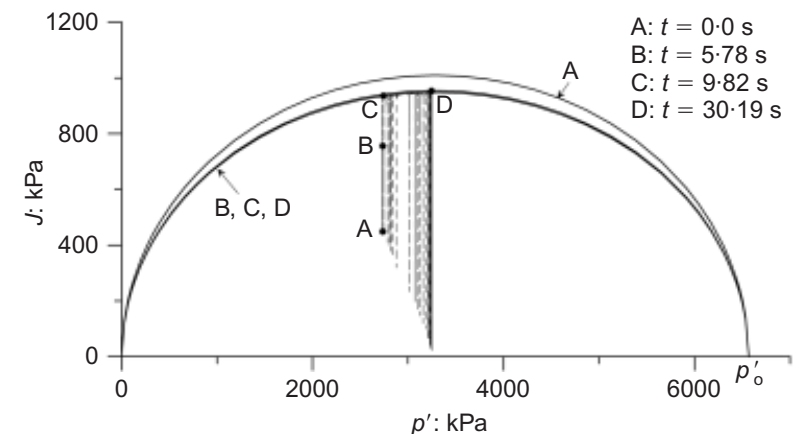

(a)

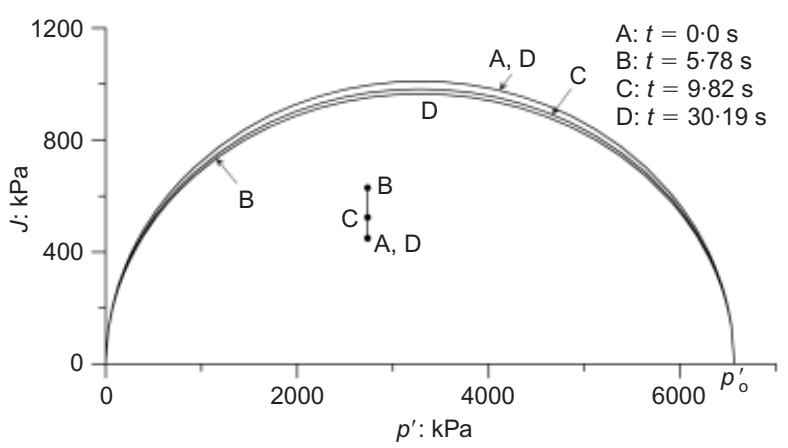

(c)

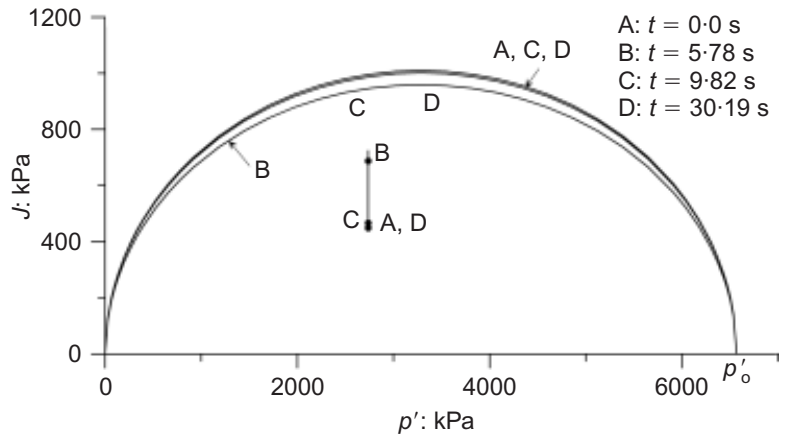

(b)

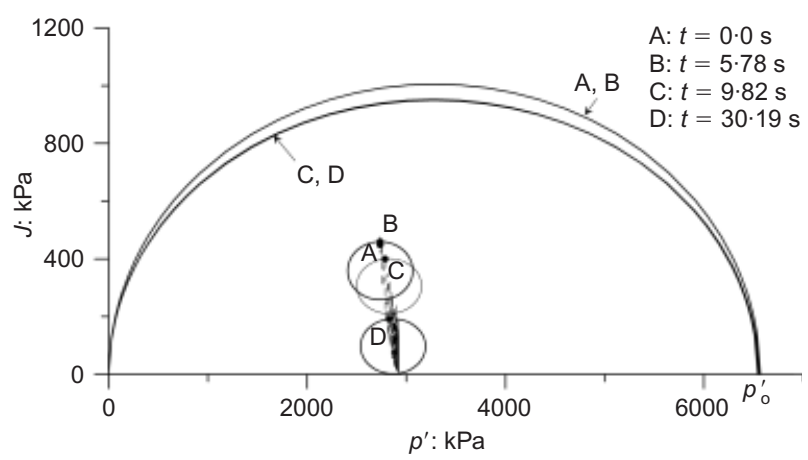

(d)

Fig. 7. $p^{\prime}-J$ stress paths of integration point at depth $z=157 \cdot 5 \mathrm{~m}$ computed with (a) MCCJ, (b) MCCJ-R, (c) MCCT and (d) M2-SKH models

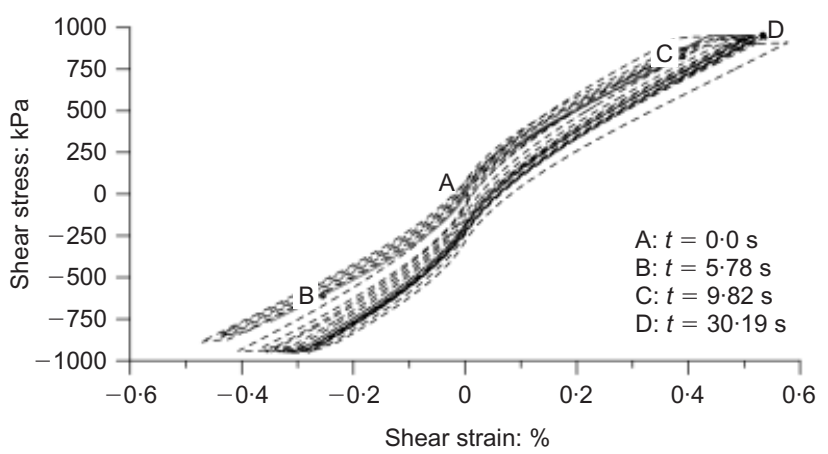

(a)

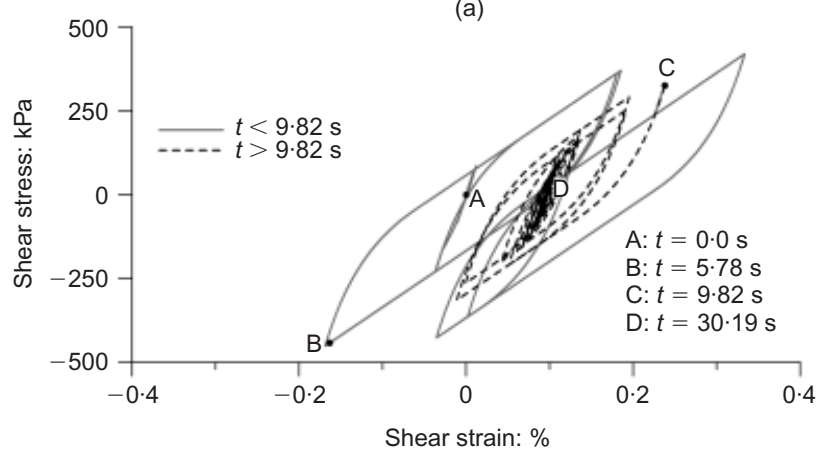

(c)

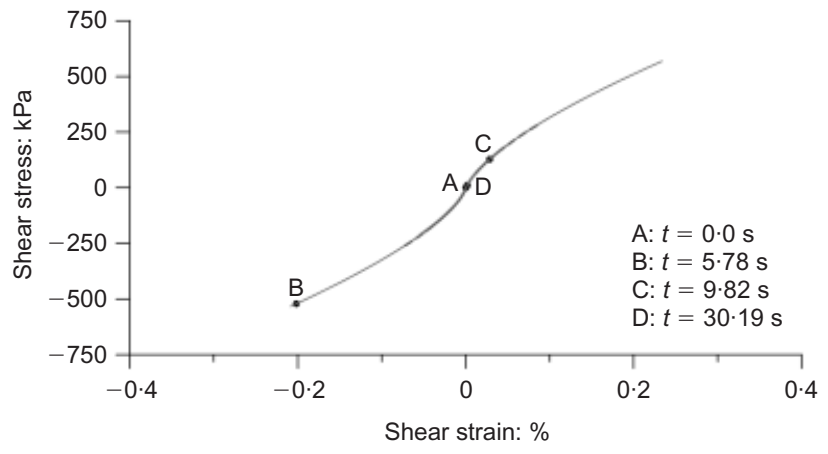

(b)

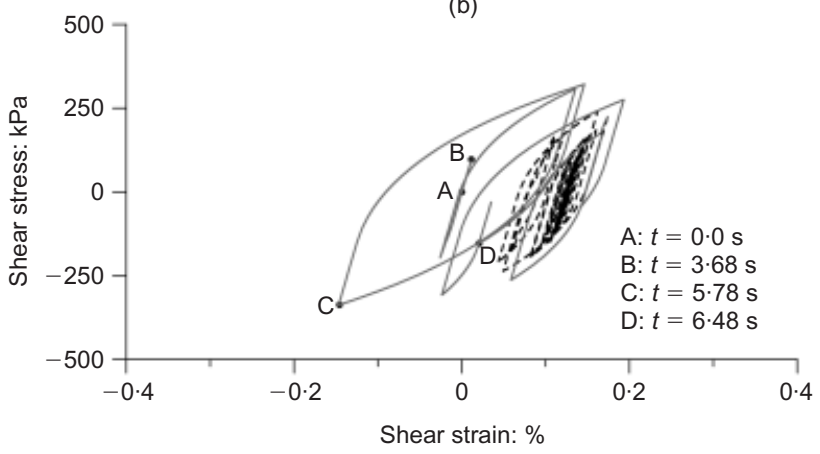

(d)

Fig. 8. Shear stress-strain curve of integration point at depth $z=157.5 \mathrm{~m}$ computed with (a) MCCJ, (b) MCCJ-R, (c) MCCTand (d) M2-SKH models

crete beams of $0.9 \%$ (Menkiti et al., 2001b). Therefore the FE results are generally in good agreement with the observed static behaviour of the tunnels.

Figure 10 shows the accumulated hoop stress distribution in the beam elements forming the tunnels' lining. Once more the MCCJ/MCJR and MCCT models give very similar hoop stress distributions around the tunnels' lining. For both tunnels the M2-SKH analysis predicts higher stresses and a different stress distribution at the spring locations. All results, however, indicate that the LBPT attracted higher 


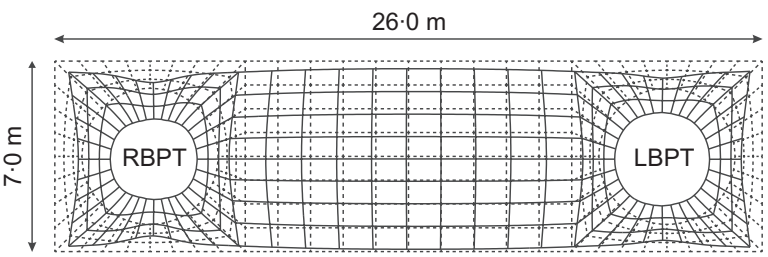

(a)

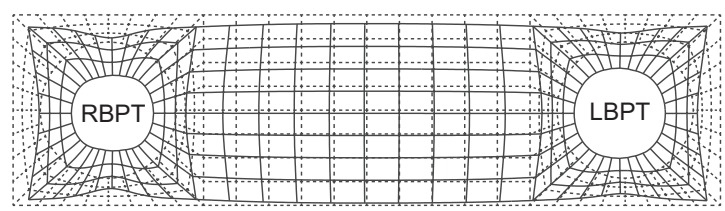

(b)

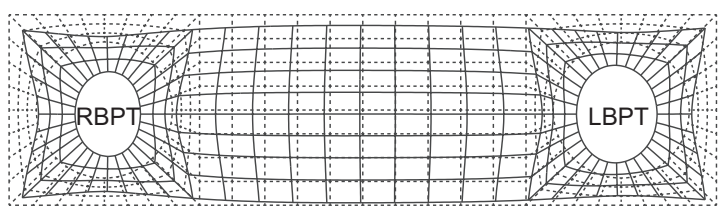

(c)

Fig. 9. Mesh configuration around tunnels at end of static analysis: (a) MCCJ/MCCJ-R; (b) MCCT; (c) M2-SKH

Table 4. Summary of horizontal diametral movements after static analysis

\begin{tabular}{l|c|c}
\hline \multirow{2}{*}{} & \multicolumn{2}{|c}{ Horizontal convergence: $\mathrm{mm}$} \\
\cline { 2 - 3 } & LBPT & RBPT \\
\hline MCCJ/MCCJ-R & $30 \cdot 6(0 \cdot 61 \%)$ & $36 \cdot 6(0 \cdot 73 \%)$ \\
MCCT & $32.9(0 \cdot 66 \%)$ & $39 \cdot 65(0 \cdot 79 \%)$ \\
M2-SKH & $40 \cdot 72(0 \cdot 81 \%)$ & $51 \cdot 86(1 \cdot 03 \%)$ \\
\hline
\end{tabular}

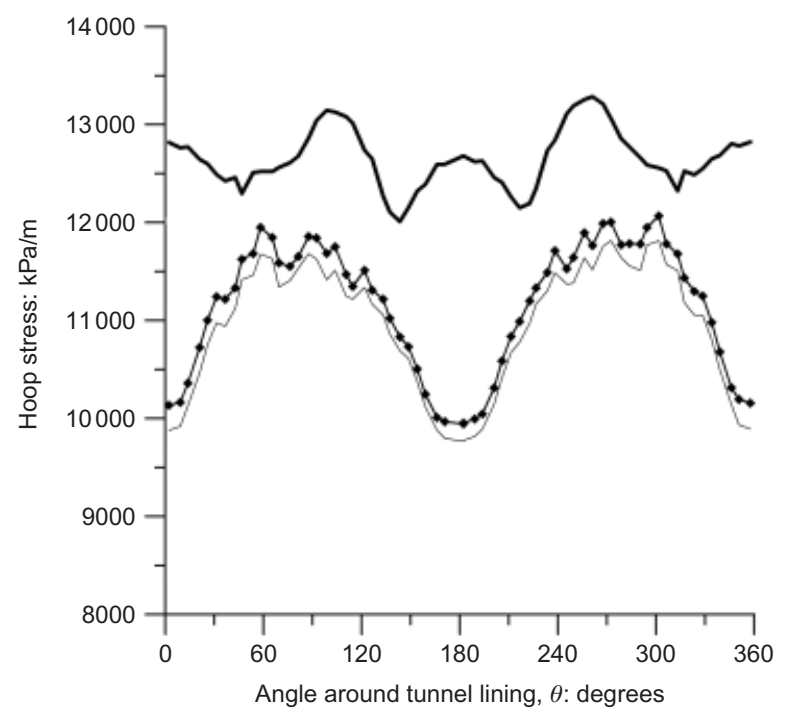

(a) loads than the RBPT. Menkiti et al. (2001b), based on the performance of the exploratory tunnel, estimated the immediate ground loads as being $40-65 \%$ of the overburden, which corresponds to hoop stresses of $7450-12120 \mathrm{kPa}$ in the tunnels' lining. The predicted hoop stresses for the RBPT lie within this range, whereas those predicted by the M2-SKH model for the LBPT are marginally above the upper limit of this range. Overall, the static behaviour predicted by all models is broadly similar, as the observed differences in movements and hoop stresses are not significant. Therefore it can be concluded that the subsequent dynamic analyses start from a similar static configuration.

\section{Dynamic analyses}

Once the static stresses acting on the tunnel linings were established, a set of dynamic analyses as previously described was undertaken, assuming that all materials behave in an undrained manner. Fig. 11 presents the maximum shear strain profiles (caused only by the dynamic excitation) in the middle of the pillar between the tunnels. Generally, these profiles are very similar to the corresponding free-field ones of Fig. 5(b). The main differences are restricted to the level of the tunnels (the centre of the tunnels is at a depth $z=160.0 \mathrm{~m}$ ), where all models predict a modified response with respect to the free-field one. Interestingly, at the level of the tunnels the difference between the MCCT and M2SKH models is much smaller than in Fig. 5(b). This is also illustrated in the shear-strain time histories plotted for an integration point adjacent to the LBPT's crown (Fig. 12); both the maxima and the permanent values of shear strain predicted by the two models are very similar. On the other hand, the MCCJ model again predicts unrealistically high levels of strain, and the MCCJ-R model gives very low values of permanent strain.

The pore water pressure time histories for the same location (i.e. LBPT's crown) show significant differences between the MCCT and M2-SKH models (Fig. 13). Starting from a negative value (suction) caused by the excava-

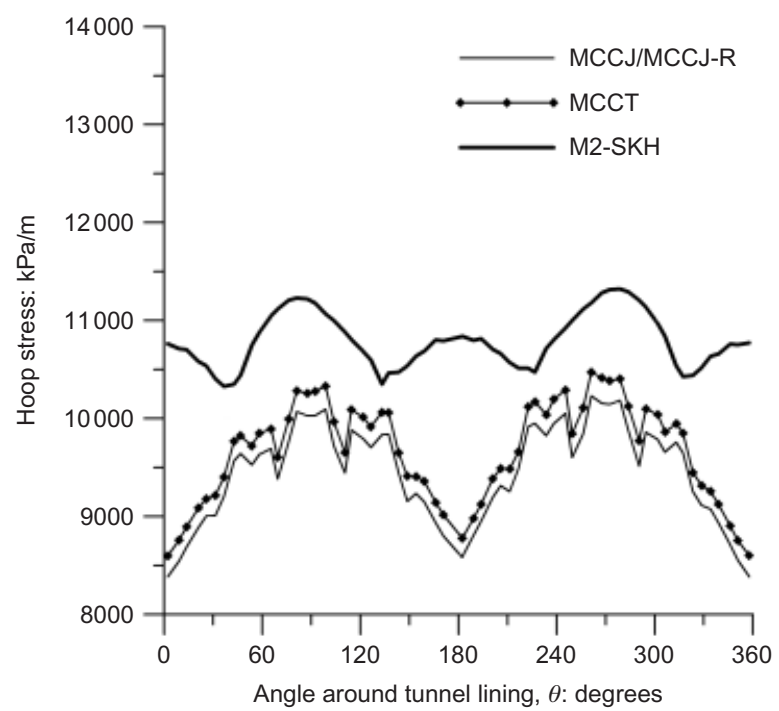

(b)

Fig. 10. Accumulated maximum hoop-stress distributions around lining of (a) LBPT and (b) RBPT at end of static analysis 


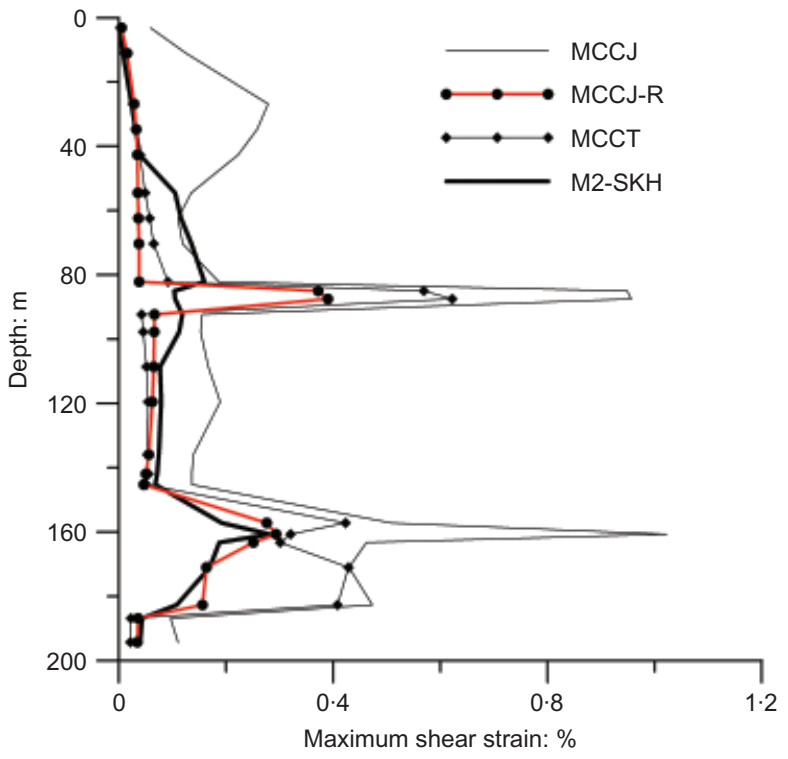

Fig. 11. Maximum shear strain profile computed in middle of pillar

tion process, the M2-SKH time history remains constant for the first few seconds of the earthquake, but close to the peak of the input excitation $(t=5 \mathrm{~s})$ an abrupt jump is observed, which results in a compressive pore water pressure. Subsequently, the compressive pore water pressure continues to build up for a few more seconds (approximately until $t=10.0 \mathrm{~s}$ ) and then stabilises. The MCCT time history starts from a lower suction, and it also remains constant for the initial part of the excitation. However, at the earthquake peak, further tensile pore water pressures are generated, which continue to accumulate up to $t=15 \mathrm{~s}$. The MCCJ-R time history starts from a high tensile value, which builds up further as the earthquake intensity increases, indicating that - unlike the corresponding one-dimensional analysis - plasticity is introduced as the stress path reaches the yield surface. Finally, as expected, the pore water pressure response predicted by the MCCJ model is dominated by unrealistically large oscillations from $\mathrm{t} \approx 10 \cdot 0 \mathrm{~s}$ onwards.

These significant differences in the predicted pore water pressure time histories between the M2-SKH and the three other models result from the very different mechanics of introducing plasticity in the models. The M2-SKH is the only one that can predict plastic deformations, and thus excess pore water pressure generation, during unloading.

The above observations can be better understood by looking at the $p^{\prime}-J$ stress paths of Fig. 14, for the integration point adjacent to the LBPT crown. As a result of the initial static loading, the dynamic analysis stress path starts on the MCC yield surface in Figs 14(a), 14(b) and 14(c), and on the small kinematic yield surface of the M2-SKH model in Fig. 14(d). Therefore, in contrast to Fig. 7(b), the MCCJ-R stress path reaches the yield surface several times, introducing plasticity in the response. The MCCJ stress path also reaches the yield surface several times, similar to Fig. 7 (a), and remains for most of the earthquake duration within the elastic region, resulting in insufficient damping of the response, as shown in Fig. 12(a). Finally, the M2-SKH stress path shows that the KYS is dragged around within the bounding surface, resulting in hysteretic behaviour and introducing plastic strains.

Analytical studies suggest that circular tunnels subjected to shear waves propagating in planes perpendicular to the tunnel

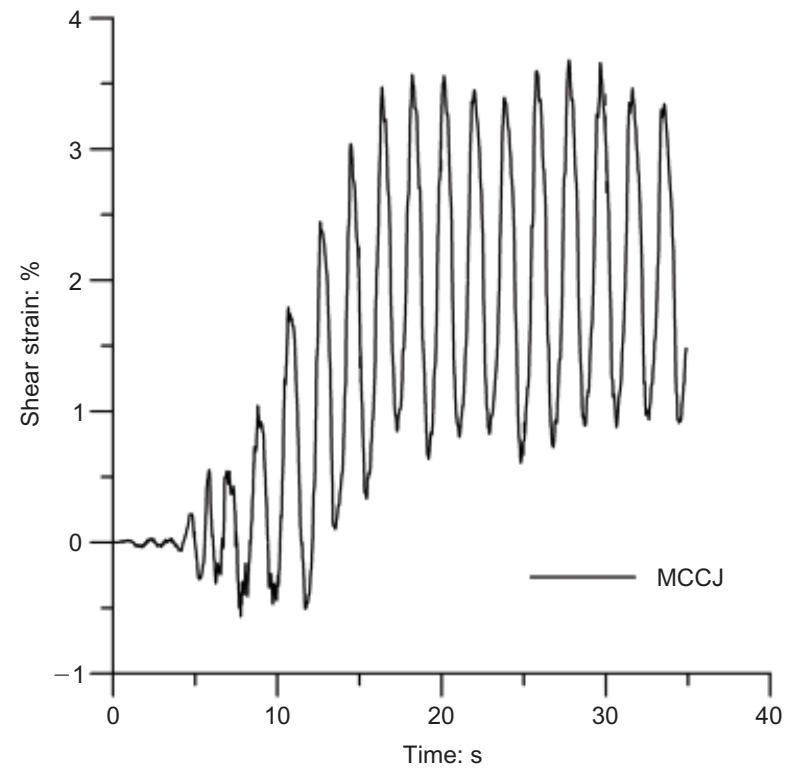

(a)

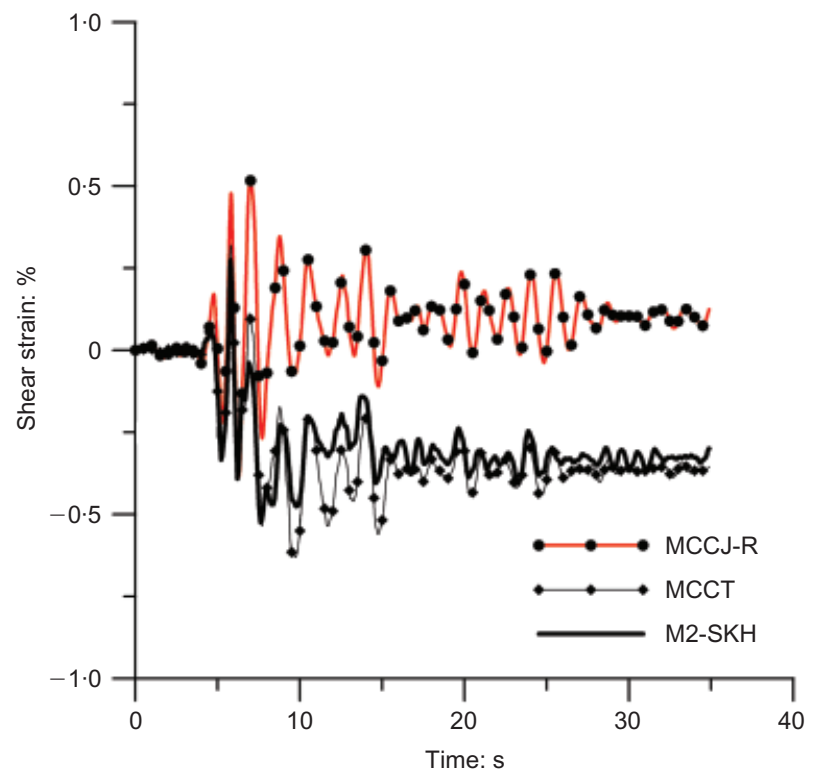

(b)

Fig. 12. Shear-strain time histories computed at integration point adjacent to crown of LBPT: (a) MCCJ; (b) MCCJ-R, MCCT, M2-SKH

axis undergo an ovalling deformation (e.g. Owen \& Scholl, 1981). For the BPTs this form of deformation was verified by post-earthquake field investigation studies (Menkiti et al., 2001a) and was also depicted by all FE analyses, irrespective of the employed constitutive model. Fig. 15 illustrates the distribution of maximum hoop stress sub-accumulated (from the onset of the excitation) around the lining of the BPTs, a few seconds after the peak of the earthquake. Clearly, the stress distribution is highly non-uniform, with its peaks occurring, for all models, at shoulder and knee locations of the lining.

Table 5 summarises the values of maximum hoop stress recorded at shoulder and knee locations $\left(\theta=137^{\circ}, 317^{\circ}\right.$ respectively) of the lining owing to static and dynamic loading. Although all models predict similar values of maximum hoop stress for the static analysis, the seismically induced maximum $\sigma_{\mathrm{H}}$ values predicted by the MCCJ model are, as expected, unrealistically high, and significantly larger 


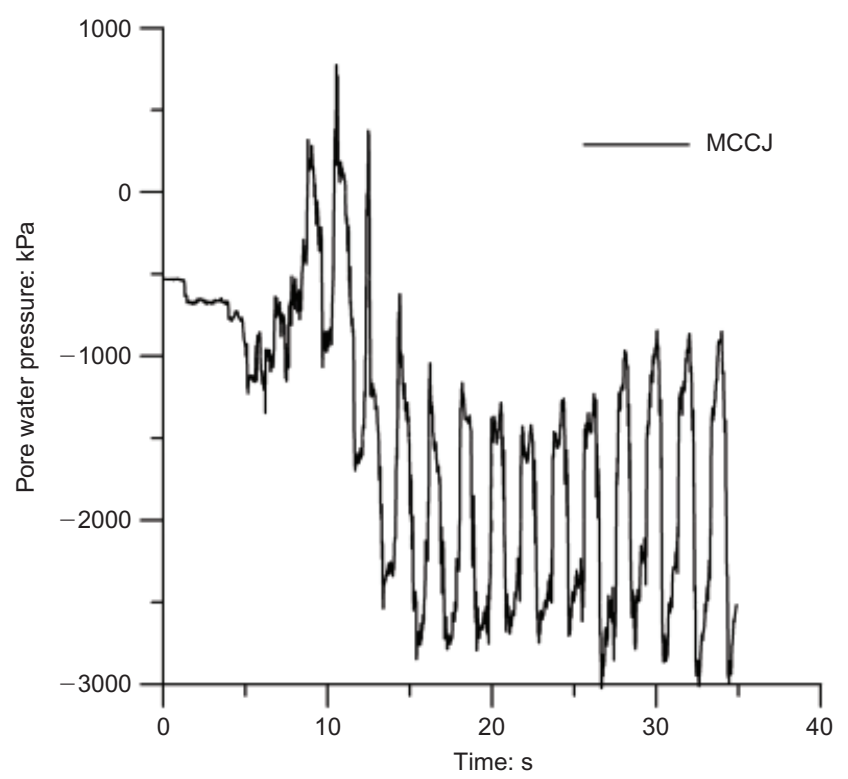

(a)

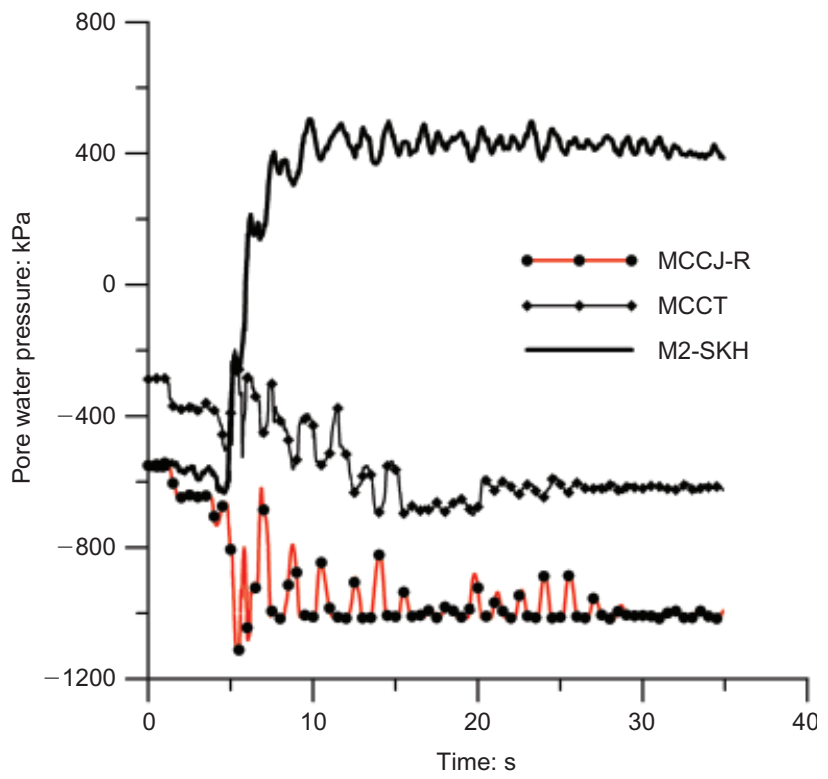

(b)

Fig. 13. Pore water pressure time histories computed at integration point adjacent to crown of LBPT: (a) MCCJ; (b) MCCJ-R, MCCT, M2-SKH

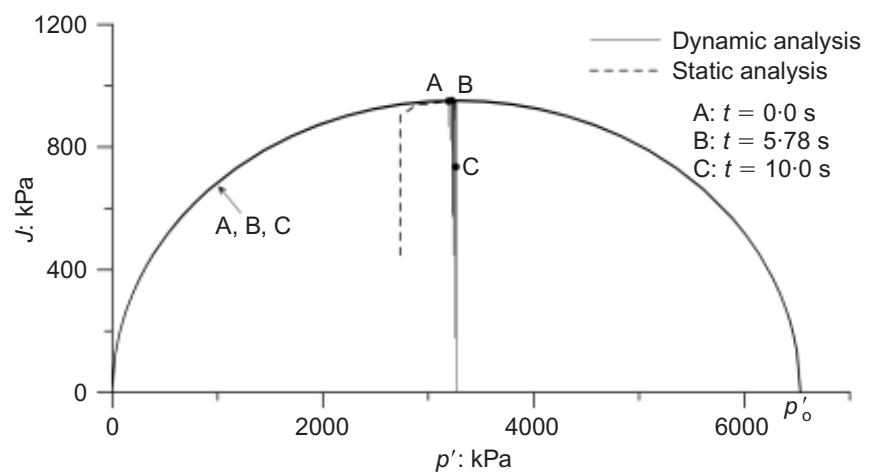

(a)

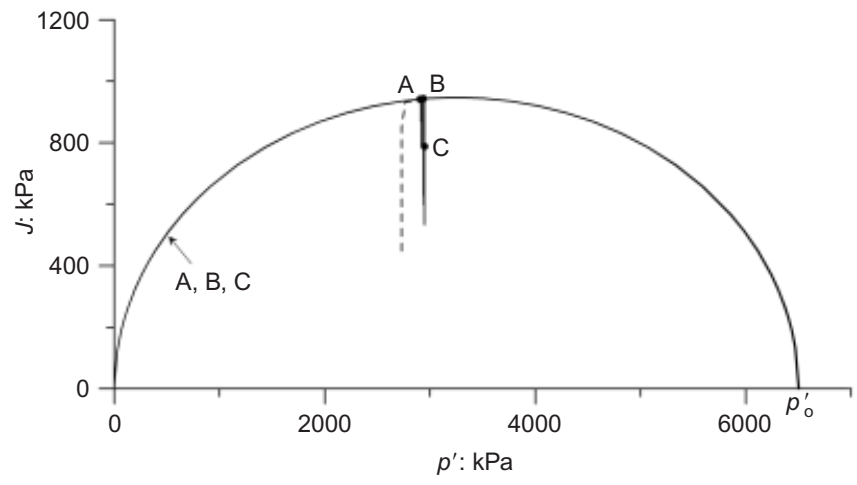

(c)

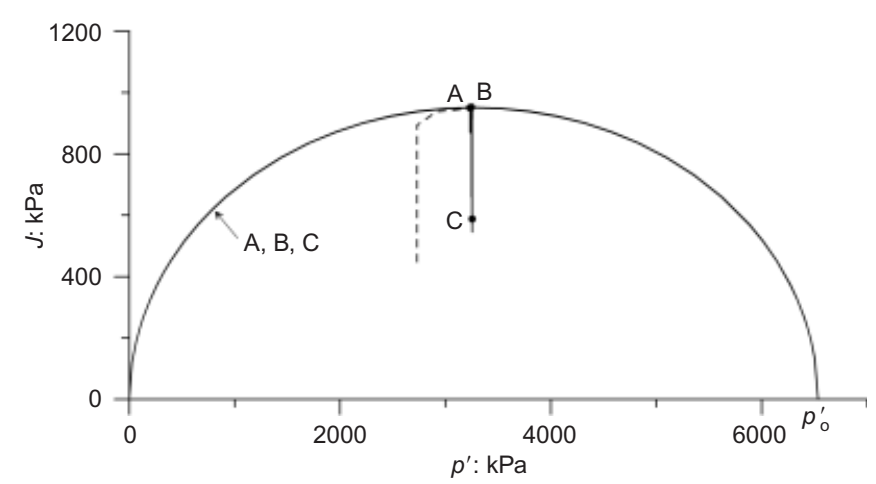

(b)

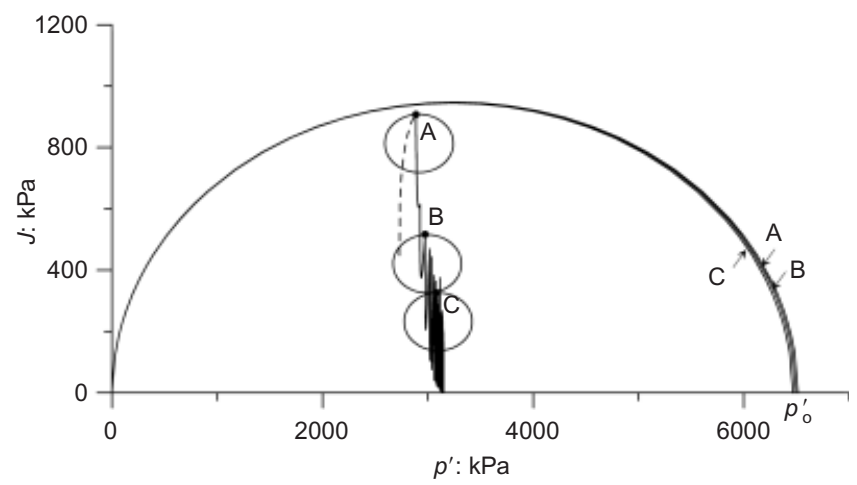

(d)

Fig. 14. $p^{\prime}-J$ stress paths of integration point adjacent to crown of LBPT computed with (a) MCCJ, (b) MCCJ-R, (c) MCCT and (d) M2-SKH models

than those computed by the three remaining models. Based on in situ measurements, the cube strength of the shotcrete was estimated to be $40 \mathrm{MPa}$ for the LBPT and $30 \mathrm{MPa}$ for the RBPT. Therefore the maximum total (i.e. static and seismic) $\sigma_{\mathrm{H}}$ values predicted by the MCCJ model exceed the concrete strength by up to about $60 \%$, if a factor of 0.85 is allowed to correct from cube strength to cylinder strength for the comparison. Such an overload would indicate a dramatic failure of the lining. The MCCJ-R analysis predicts total $\sigma_{\mathrm{H}}$ values close to but somewhat below the concrete strength for the LBPT, indicating that the lining could withstand the seismic loading, while the total $\sigma_{\mathrm{H}}$ values of the MCCT model lie closer to the concrete strength. Finally, the stress values predicted by the M2-SKH model just exceed 


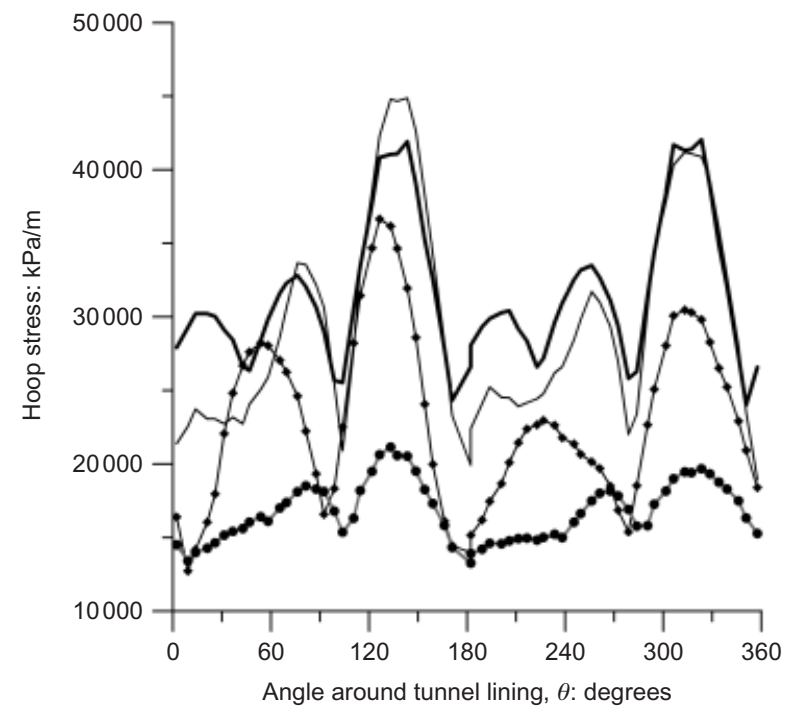

(a)

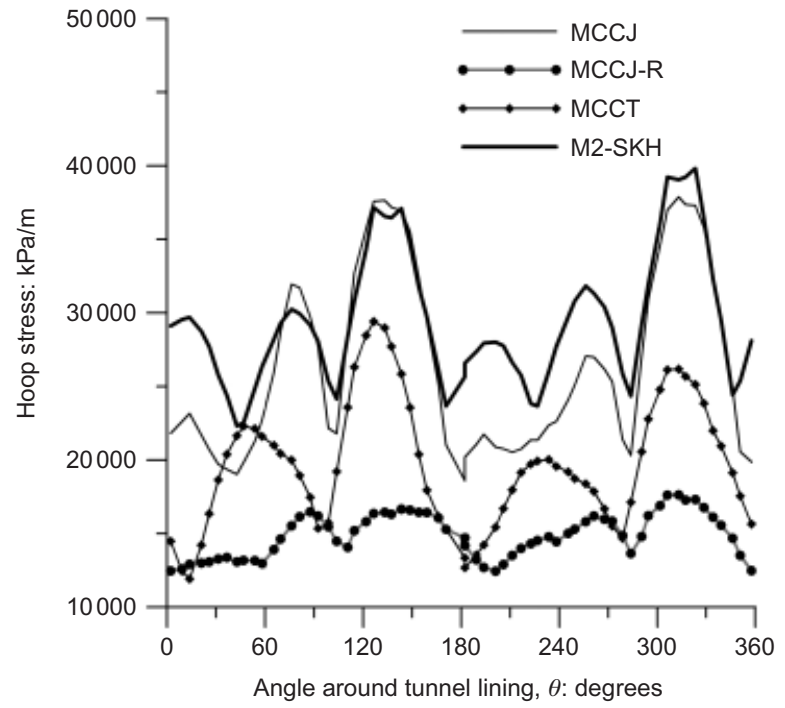

(b)

Fig. 15. Sub-accumulated (from onset of excitation) maximum hoop stress distribution around tunnels' lining at $t=10 \cdot 0 \mathrm{~s}$ : (a) LBPT; (b) RBPT

Table 5. Summary of maximum stress at shoulder and knee locations of BPTs' lining

\begin{tabular}{|c|c|c|c|c|c|c|c|c|c|c|c|}
\hline \multirow[t]{3}{*}{ Location } & \multicolumn{11}{|c|}{ Maximum hoop stress, $\sigma_{\mathrm{H}}: \mathrm{MPa}$} \\
\hline & \multicolumn{3}{|c|}{ Static } & \multicolumn{4}{|c|}{ Earthquake } & \multicolumn{4}{|c|}{ Total } \\
\hline & $\mathrm{MCCJ} / \mathrm{MCCJ}-\mathrm{R}$ & MCCT & M2-SKH & MCCJ & MCCJ-R & MCCT & M2-SKH & MCCJ & MCCJ-R & $\mathrm{MCCT}$ & M2-SKH \\
\hline LBPT shoulder $\left(\theta=137^{\circ}\right)$ & $10 \cdot 9$ & $11 \cdot 0$ & $12 \cdot 1$ & $52 \cdot 7$ & $22 \cdot 0$ & $25 \cdot 3$ & $29 \cdot 2$ & $63 \cdot 6$ & $32 \cdot 9$ & $36 \cdot 3$ & $41 \cdot 3$ \\
\hline LBPT knee $\left(\theta=317^{\circ}\right)$ & $11 \cdot 3$ & $11 \cdot 4$ & $12 \cdot 5$ & $63 \cdot 8$ & $20 \cdot 3$ & $20 \cdot 6$ & $29 \cdot 0$ & $75 \cdot 1$ & $31 \cdot 6$ & 32 & $41 \cdot 5$ \\
\hline RBPT shoulder $\left(\theta=137^{\circ}\right)$ & $9 \cdot 9$ & $10 \cdot 6$ & $10 \cdot 5$ & $57 \cdot 3$ & $17 \cdot 5$ & $20 \cdot 0$ & $26 \cdot 4$ & $67 \cdot 2$ & $27 \cdot 4$ & $30 \cdot 6$ & $36 \cdot 9$ \\
\hline RBPT knee $\left(\theta=317^{\circ}\right)$ & $9 \cdot 7$ & $9 \cdot 8$ & $10 \cdot 5$ & $47 \cdot 2$ & $18 \cdot 1$ & $17 \cdot 9$ & $29 \cdot 6$ & $56 \cdot 9$ & $27 \cdot 8$ & $27 \cdot 7$ & $40 \cdot 1$ \\
\hline
\end{tabular}

the strength of the shotcrete, and thus agree with the field observations of partial collapse. All models predict $\sigma_{\mathrm{H}}$ values that are consistently higher for the LBPT than for the RBPT, which is also in agreement with field observations suggesting that the LBPT experienced more severe damage than the RBPT.

It is interesting to note that the seismically induced hoop stress values predicted in the two-dimensional analyses in Table 5 by the MCCJ, MCCJ-R and MCCT models are consistently lower than the corresponding ones predicted by the analytical solution in Table 3. This is despite the fact that the presence of the second tunnel is ignored by the analytical solution. As the static loading is accounted for in the two-dimensional analyses, the dynamic stress paths in those three models start from a point on the MCC yield surface, introducing plasticity and thus limiting the predicted loading in the lining. In the corresponding one-dimensional analyses the introduced plasticity is either limited or non-existent. Interestingly, the hoop stresses predicted by the M2-SKH two-dimensional analysis are slightly higher than those predicted by the corresponding analytical solution. The KYS introduces plasticity during the dynamic analysis even in the small-strain range, irrespective of the initial stress state of the soil. Conse- quently, the difference between the one-dimensional and two-dimensional analyses results in terms of maximum shear strain at the level of the tunnels is not very significant, and can be partly attributed to the interaction of the two tunnels.

Figures 16 and 17 present, respectively, the bending moment and thrust time histories developed by seismic loading at $\theta=137^{\circ}$ (shoulder location) of the LBPT for all models. The MCCJ model predicts some permanent loads (mainly in terms of thrust), but overall the behaviour seems to be effectively elastic. As for the corresponding onedimensional analysis, the introduced plasticity in the MCCJ analysis does not provide adequate damping in the response, leading to substantial overestimation of the seismic loads acting on the tunnel lining. The introduction of Rayleigh damping in the MCCJ-R analysis limits the magnitude of the predicted loads, while the model also predicts some small permanent loads. Interestingly, the MCCT and M2SKH models predict very similar bending moment variations, but the predicted thrust-time histories differ significantly, with the MCCT model giving much lower permanent thrust values. It should be noted that significant locked-in thrusts and bending moments were measured in Bolu in instrumented linings in other materials. 


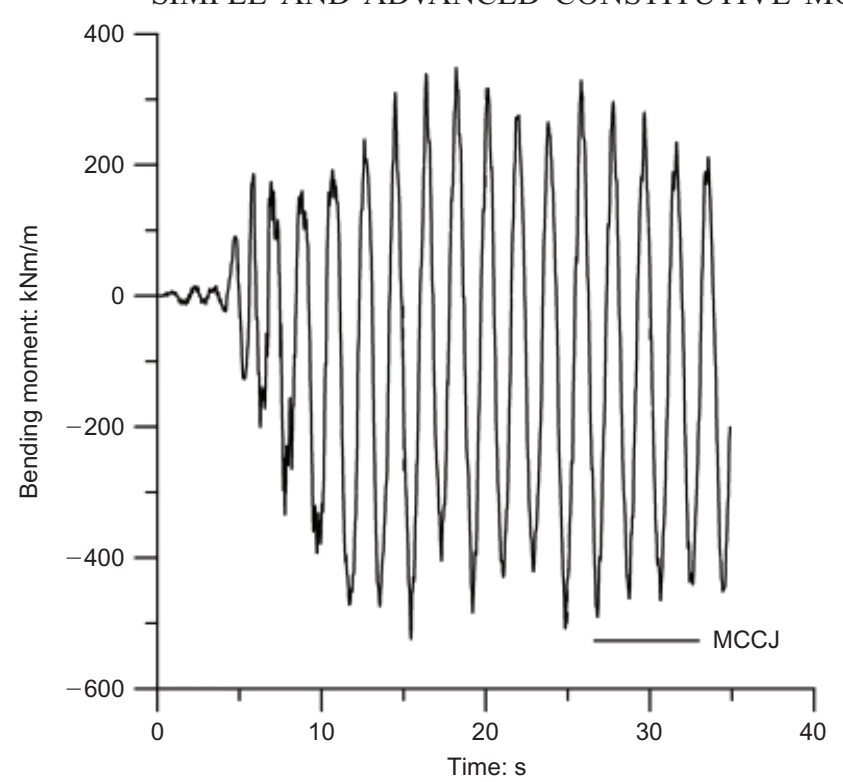

(a)

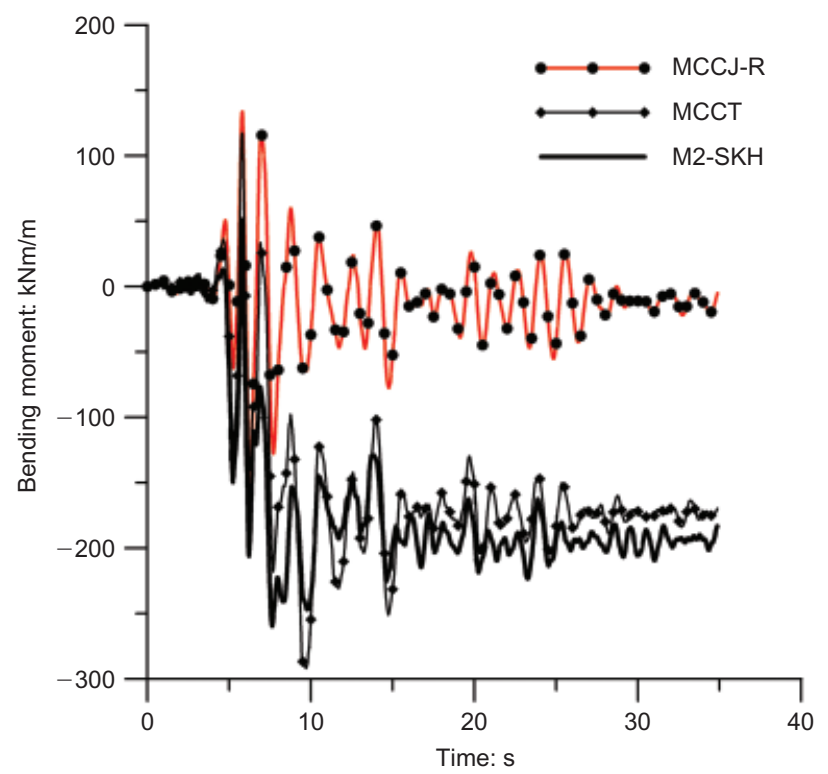

(b)

Fig. 16. Bending moment time histories at shoulder of LBPT computed with: (a) MCCJ model; (b) MCCJ-R, MCCT and M2-SKH models

\section{CONCLUSIONS}

In this paper a section of the Bolu tunnels, which was severely damaged during the 1999 Duzce earthquake, was analysed with the finite-element code ICFEP using four constitutive modelling approaches of ranging complexity: a simple elasto-plastic constitutive model (modified Cam-clay), with and without Rayleigh damping; the same model coupled with a cyclic non-linear model that can simulate pre-yield non-linear elastic hysteresis; and finally an advanced kinematic hardening model.

Simple site response finite-element analyses were first undertaken for the studied site to demonstrate some fundamental features of the employed constitutive models, paying particular attention to the calibration of the Rayleigh damping parameters. A rigorous calibration procedure for the selection of the target damping ratio and the Rayleigh damping parameters was demonstrated. It is suggested that this procedure be followed prior to any finite-element analy-

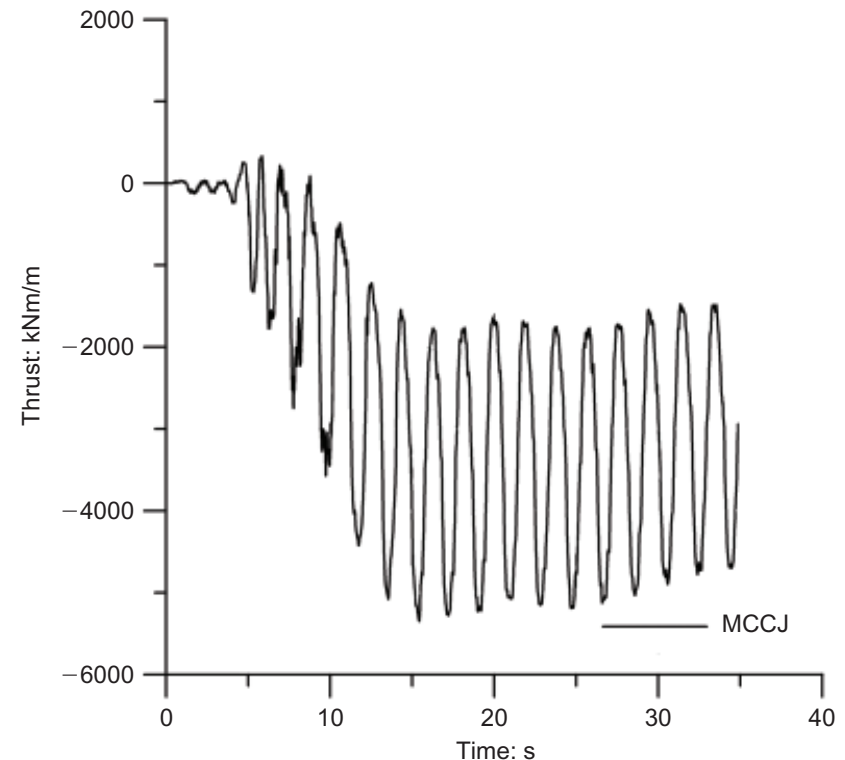

(a)

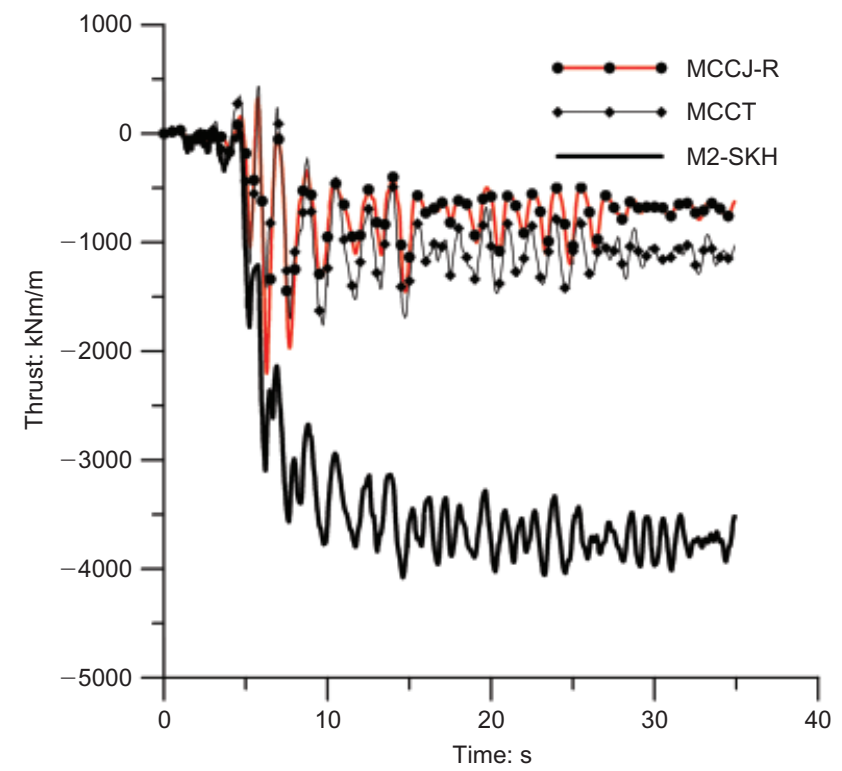

(b)

Fig. 17. Thrust time histories at shoulder of LBPT computed with: (a) MCCJ model; (b) MCCJ-R, MCCT and M2-SKH models

sis using this type of damping, rather than using rules of thumb for the selection of the Rayleigh damping parameters.

The one-dimensional analysis results, in terms of maximum shear strain, were also used as an input to an analytical method (extended Hoeg method) for calculating the bending and thrust moments acting on the tunnel lining. It was shown that the predicted loads depend significantly on the constitutive model used to compute the free-field shear deformations. Furthermore, when compared with the twodimensional analyses results of the three simplest models (i.e. MCCJ, MCCJ-R and MCCT), the analytical method was found to predict significantly higher hoop stresses.

Regarding the performance of the examined constitutive models, the FE analyses showed the following.

(a) The plasticity induced during the dynamic analysis with the MCCJ model is not adequate to mimic the hysteretic behaviour of the soil, and thus all predicted 
time histories resemble undamped elastic response. Consequently, the MCCJ model significantly overpredicts the transient loads acting on the tunnels' lining during the earthquake, and possibly underpredicts the permanent locked-in loads following the earthquake. This highlights the inadequacy of simple elasto-plastic models for dynamic analysis.

(b) The response predicted by the MCCJ-R model, in the one-dimensional case, was governed by the introduced Rayleigh damping, while the role of plasticity was either redundant or insignificant. Therefore the reliability of the MCCJ-R model results in terms of predicting permanent movements or loads is very limited. Furthermore, the maximum hoop stress predicted for the LBPT by the two-dimensional MCCJ-R analysis was below the estimated concrete strength, suggesting that the model underestimated the seismically induced loads that were acting on the tunnels' lining at failure.

(c) The MCCT model captured basic facets of soil behaviour when subjected to dynamic loading such as hysteric damping, and gave reasonable predictions of the seismically induced hoop stresses acting in the tunnels' lining. The generation of excess pore water pressures and plastic strains, however, was very much dependent on the proximity of the initial stress state of the soil to the yield surface.

(d) The M2-SKH model appropriately captured features of the soil behaviour when subjected to cyclic loading such as pore pressure generation, hysteretic damping and plastic deformation during unloading, and consequently gave reasonable predictions for the seismically induced loads on the tunnels' lining.

\section{APPENDIX: MATERIAL PARAMETERS FOR THE TABORDA ET AL. (2009) MODEL}

The stress-strain curve of the Taborda et al. (2009) model is a hyperbolic function that in general stress space is described by the equation

$$
J=J_{\mathrm{r}}+\frac{G_{\max }\left(E_{\mathrm{d}}-E_{\mathrm{d}, \mathrm{r}}\right)}{1+\left(\alpha_{1} / n\right)\left|E_{\mathrm{d}}-E_{\mathrm{d}, \mathrm{r}}\right|}
$$

where $J$ and $E_{\mathrm{d}}$ are the current values of the second invariant of the stress and strain tensors respectively; $J_{\mathrm{r}}$ and $E_{\mathrm{d}, \mathrm{r}}$ are the values of the same invariants at the last reversal point; $\alpha_{1}$ is a model parameter controlling the degradation of the stiffness; and $n$ is a scaling factor. The scaling factor is equal to 1 for initial loading, and changes to 2 upon detection of the first unloading. The degradation of the bulk modulus was based on the degradation of the shear modulus, adopting a Poisson ratio of $0 \cdot 3$ for all layers. The implementation of the model allows the user to define a minimum value of the tangent shear modulus. Table 6 summarises the values of the parameter $\alpha_{1}$ and of $G_{\min }$ for all layers, and Fig. 18 shows the resulting normalised secant stiffness variation for the middle of each layer.

Table 6. Model parameters for the Taborda et al. model

\begin{tabular}{l|c|c}
\hline Layer & $\alpha_{1}$ & $G_{\min }: \mathrm{MPa}$ \\
\hline 1 & 1239 & 152 \\
2 & 3444 & $53 \cdot 7$ \\
3 & 1226 & $215 \cdot 9$ \\
4 & 2327 & $168 \cdot 4$ \\
5 & 1239 & $486 \cdot 0$ \\
\hline
\end{tabular}

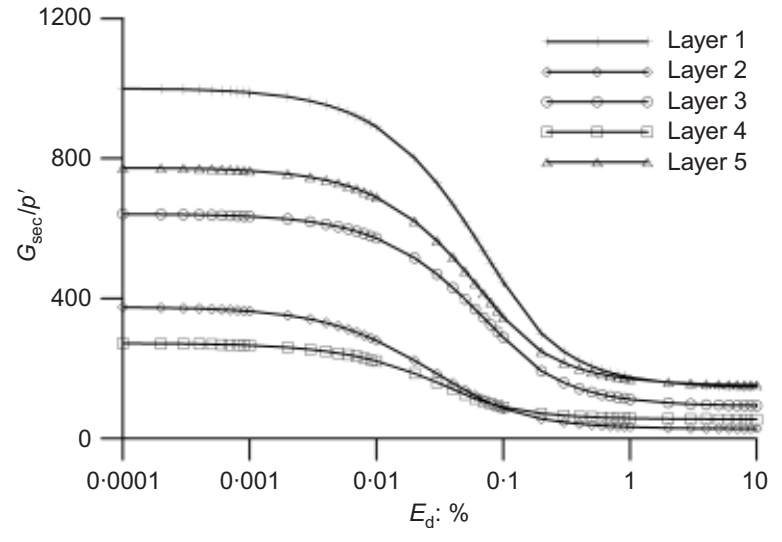

Fig. 18. Normalised secant shear stiffness-strain curves of Taborda et al. model

\section{NOTATION}

$A$ area per unit width of lining cross-section

$c^{\prime}$ cohesion intercept of a soil

$E$ Young's modulus

$E_{\mathrm{d}}$ deviatoric strain invariant

$f$ frequency

$G$ shear modulus

$G_{\max }, G_{\min }$ maximum and minimum values of shear modulus

$H$ depth of soil layer

I moment of inertia

$J$ deviatoric stress

$K$ bulk modulus

$K_{0} \quad$ coefficient of earth pressure at rest

$M$ bending moment in tunnel lining

$M_{\max }$ maximum bending moment in tunnel lining

$p^{\prime}$ mean effective stress

PI plasticity index

$R_{\mathrm{b}}, \alpha_{\mathrm{o}}$ M2-SKH model parameters that define behaviour of kinematic surface

$S_{\mathrm{u}} \quad$ undrained strength

$T$ thrust in tunnel lining

$T_{\max }$ maximum thrust in tunnel lining

$t$ thickness of tunnel lining

$\Delta t$ incremental time step

$V_{\mathrm{s}}$ shear wave velocity

$v_{1} \quad$ Specific volume at unit pressure

$\alpha, \beta$ Rayleigh damping parameters

$\alpha_{1}, n$ constants of the Taborda et al. model

$\gamma$ bulk unit weight of soil

$\gamma_{\max }$ maximum free-field shear strain

$\theta$ Lode's angle

$\kappa$ slope of swelling line

$\lambda$ slope of virgin compression line

$v$ Poisson's ratio

$\rho$ mass density

$\sigma_{\mathrm{H}}$ maximum hoop stress

$\sigma_{\mathrm{v}}^{\prime} \quad$ vertical effective stress

$\phi^{\prime}$ angle of internal shearing resistance of a soil

$\omega$ angular frequency

\section{REFERENCES}

Al-Tabbaa, A. \& Wood, D. M. (1989). An experimentally based bubble model for clay. Proc. 3rd Int. Symp. on Numerical Models in Geomechanics (NUMOG III), Niagara Falls, 91-99.

Amorosi, A. \& Boldini, D. (2009). Numerical modelling of the transverse dynamic behaviour of circular tunnels in clayey soils. Soil Dynam. Earthquake Engng 29, No. 6, 1059-1072.

Bardet, J. P., Ichii, K. \& Lin, C. H. (2000). EERA: A computer program for equivalent linear earthquake site response analysis of layered soils deposits. Los Angeles: University of Southern California. 
Chopra, A. K. (2001). Dynamics of structures: Theory and applications to earthquake engineering. Englewood Cliffs, NJ: Prentice Hall.

Chung, J. \& Hulbert, G. M. (1993). A time integration algorithm for structural dynamics with improved numerical dissipation: the generalized- $\alpha$ method. J. Appl. Mech. 60, No. 2, 371-375.

Elia, G., Amorosi, A. \& Chan, A. H. C. (2005). Fully coupled dynamic analysis of an earth dam using a complex constitutive assumption. Proc. 11th Int. Conf. of IACMAG, Turin 3, 257264.

Grammatikopoulou, A., Zdravkovic, L. \& Potts, D. M. (2006). General formulation of two kinematic hardening constitutive models with a smooth elastoplastic transition. Int. J. Geomech. 6, No. 5, 291-302.

Hashash, Y. M. A., Hook, J. J., Schmidt, B. \& Yao, J.I.-C. (2001). Seismic design and analysis of underground structures. Tunnelling Underground Space Technol. 16, No. 4, 247-293.

Hoeg, K. (1968). Stresses against underground structural cylinders. J. Soil Mech. Found. Div. ASCE 94, No. 4, 833-858.

Hwang, J.-H. \& Lu, C.-C. (2007). Seismic capacity assessment of old Sanyi railway tunnels. Tunnelling Underground Space Technol. 22, No. 4, 433-449.

Jardine, R. J., Potts, D. M., Fourie, A. B. \& Burland, J. B. (1986). Studies of the influence of non-linear stress-strain characteristics in soil-structure interaction. Géotechnique 36, No. 3, 377-396, doi: 10.1680/geot.1986.36.3.377.

Kontoe, S., Zdravković, L., Potts, D. M. \& Menkiti, C. O. (2008a). Case study on seismic tunnel response. Can. Geotech. J. 45, No. $12,1743-1764$.

Kontoe, S., Zdravković, L. \& Potts, D. M. (2008b). An assessment of time integration schemes for dynamic geotechnical problems. Comput. Geotech. 35, No. 2, 253-264.

Kontoe, S., Zdravkovic, L., Potts, D. M. \& Menkiti, C. O. (2009). Comparison of constitutive models through a case study on seismic response of tunnels. Proceedings of the international conference on performance-based design in earthquake geotechnical engineering: From case history to practice, Tokyo, pp. 1051-1059.

Kwok, A. O., Stewart, J. P., Hashash, Y. M. A., Matasovic, N., Pyke, R., Wang, Z. \& Yang, Z. (2007). Use of exact solutions of wave propagation problems to guide implementation of nonlinear seismic ground response analysis procedures. J. Geotech. Geoenviron. Engng ASCE 133, No. 11, 1385-1397.

Leger, P. \& Javanmardi, F. (2007). Seismic stability of concrete gravity dams strengthened by rockfill buttressing. Soil Dynam. Earthquake Engng 27, No. 3, 274-290.

Madabhushi, S. P. G. \& Zeng, X. (2006). Seismic response of flexible cantilever retaining walls with dry backfill. Geomech. Geoengng 1, No. 4, 275-289.

Menkiti, C. O., Mair, R. J. \& Miles, R. (2001b). Tunneling in complex ground conditions in Bolu, Turkey. Proc. Underground Construction 2001 Symp., London, 546-558.

Menkiti, C. O., Sanders, P., Barr, J., Mair, R. J., Cilingir, M. \& James, S. (2001a). Effects of the 12th November 1999 Duzce earthquake on the stretch 2 of the Gumusova-Gerede Motorway in Turkey. Proc. International Road Federation 14th World Road Cong., Paris, CD-ROM.
Ni, B. (2007). Implementation of a bubble model in FLAC and its application in dynamic analysis. PhD thesis, Department of Civil and Environmental Engineering, University of Auckland, New Zealand.

O’Rourke, T. D., Goh, S. H., Menkiti, C. O. \& Mair, R. J. (2001). Highway tunnel performance during the 1999 Duzce earthquake. Proc. 15th Int. Conf. Soil Mech. Geotech. Engng, Istanbul 2, $1365-1368$.

Owen, G. N. \& Scholl, R. E. (1981). Earthquake engineering of large underground structures, Report No. FHWA/RD-80/195. Washington, DC: Federal Highway Administration and National Science Foundation.

Pakbaz, M. C. \& Yareevan, A. (2005). 2-D analysis of circular tunnel against earthquake loading. Tunnelling Underground Space Technol. 20, No. 5, 411-417.

Panet, M. \& Guenot, A. (1982). Analysis of convergence behind the face of a tunnel. Proc. Tunnelling '82, London, 197-204.

Pellet, F., Hosseini, K. A., Jafari, M. K., Zerfa, F. Z., Mahdavifar, M. R. \& Bakhshayesh, M. K. (2005). Geotechnical performance of Qanats during the 2003 Bam, Iran, earthquake. Earthquake Spectra 21, No. S1, S137-S164.

Potts, D. M. \& Zdravkovic, L. T. (1999). Finite element analysis in geotechnical engineering: Theory. London: Thomas Telford.

Potts, D. M. \& Zdravkovic, L. T. (2001). Finite element analysis in geotechnical engineering: Application: London: Thomas Telford.

Rampello, S., Cascone, E. \& Grosso, N. (2009). Evaluation of the seismic response of a homogeneous earth dam. Soil Dynam. Earthquake Engng 29, No. 5, 782798.

Roscoe, K. H. \& Burland, J. B. (1968). On the generalized stressstrain behavior of 'wet' clay. In Engineering plasticity (eds J. Heyman and F. A. Leckie), pp. 535-609. Cambridge: Cambridge University Press.

Schwartz, C. W. \& Einstein, H. H. (1980). Improved design of tunnel supports. Vol. 1: Simplified analysis for ground-structure interaction in tunneling, Report No. UMTA-MA-06-0100-80-4. Washington, DC: Urban Mass Transportation Administration.

Seed, H. B., Wong, R. T., Idriss, I. M. \& Tokimatsu, K. (1986). Moduli and damping factors for dynamic analyses of cohesionless soils. J. Geotech. Engng Div. ASCE 112, No. GTI1, 10161032.

Sun, Y., Klein, S., Caulfield, J., Romero, V. \& Wong, J. (2008). Seismic analysis of the Bay tunnel. Proc. of Geotechnical Earthquake Engineering and Soil Dynamics IV, Sacramento, CA, 111.

Taborda, D., Kontoe, S., Zdravković, L. \& Potts, D. M. (2009). Application of cyclic nonlinear elastic models to site response analysis. Proc. 1st Int. Symp. on Computational Geomechanics, Juan-les-Pins, 956-966.

Vucetic, M. \& Dobry, R. (1991). Effect of soil plasticity on cyclic response. J. Geotech. Engng ASCE 117, No. 1, 89-107.

Wang, J. N. (1993). Seismic design of tunnels: A state-of-the-art approach, Monograph 7. New York: Parsons, Brinckerhoff, Quade and Douglas, Inc.

Zerwer, A., Cascante, G. \& Hutchinson, J. (2002). Parameter estimation in finite element simulations of Rayleigh waves. J. Geotech. Geoenviron. Engng 128, No. 3, 250-261. 